\title{
Biomimetic Mn-Catalases Based on Dimeric Manganese Complexes in Mesoporous Silica for Potential Antioxidant Agent
}

† Laboratoire de Chimie, ENS de Lyon, Université de Lyon, 46 Allée d'Italie, 69364 Lyon Cedex 07, France

† Departament de Química Inorgànica and §Crystal·lografia, Mineralogia i Dipòsits Minerals, Universitat de Barcelona, 08028 Barcelona, Spain

|| Institut de Ciència Molecular, Universitat de València, C/Catedrático José Beltrán 2, 46980 Paterna, Spain 
Two new structural and functional models of the Mn-catalase with formula $[\{\mathrm{MnIII}(\mathrm{bpy})(\mathrm{H} 2 \mathrm{O})\}(\mu-2-$ $\mathrm{MeOC} 6 \mathrm{H} 4 \mathrm{CO} 2) 2(\mu-\mathrm{O})\{\mathrm{MnIII}(\mathrm{bpy})(\mathrm{X})\}] \mathrm{X}$, where $\mathrm{X}=\mathrm{NO} 3(1)$ and $\mathrm{ClO} 4$ (2) and bpy $=2,2^{\prime}$-bipyridine, were synthesized and characterized by X-ray diffraction. In both cases, a water molecule and an $\mathrm{X}$ ion occupy the monodentate positions. The magnetic properties of these compounds reveal a weak antiferromagnetic behavior ( $2 \mathrm{~J}=-2.2 \mathrm{~cm}-1$ for 1 and $-0.7 \mathrm{~cm}-1$ for 2 , using the spin Hamiltonian $\mathrm{H}=$ $-2 \mathrm{~J} \mathrm{~S} 1 \cdot \mathrm{S} 2)$ and negative zero-field splitting parameter DMn $(-4.6 \mathrm{~cm}-1$ and $-3.0 \mathrm{~cm}-1$ for 1 and 2 , respectively). This fact, together with the nearly orthogonal orientation of the Jahn-Teller axes of the MnIII ions explain the unusual shape of $\chi$ MT versus T plot at low temperature. Compound 1 presents a better catalase activity than 2 in $\mathrm{CH} 3 \mathrm{CN}-\mathrm{H} 2 \mathrm{O}$ media, probably due to a beneficial interaction of the NO3 - ion with the Mn complex in solution. These compounds were successfully inserted inside twodimensional hexagonal mesoporous silica (MCM-41 type) leading to the same hybrid material ([Mn2O]@SiO2), without the X group. The manganese complex occupies approximately half of the available pore volume, keeping the silica's hexagonal array intact. Magnetic measurements of [Mn2O]@SiO2 suggest that most of the dinuclear unit is preserved, as a non-negligible interaction between $\mathrm{Mn}$ ions is still observed. The X-ray photoelectron spectroscopy analysis of the Mn 3s peak confirms that $\mathrm{Mn}$ remains as MnIII inside the silica. The catalase activity study of material [Mn2O]@SiO2 reveals that the complex is more active inside the porous silica, probably due to the surface silanolate groups of the pore wall. Moreover, the new material shows catalase activity in water media, while the coordination compounds are not active.

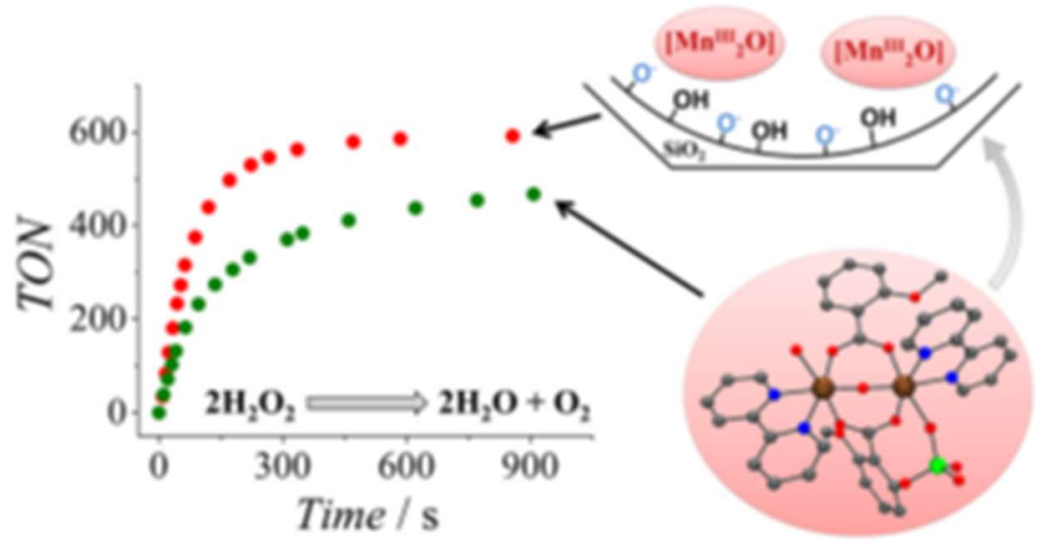


54 Reactive oxygen species (ROS), represented by superoxide ( $\left.\mathrm{O} 2 \bullet^{\bullet}\right)$, hydrogen peroxide $(\mathrm{H} 2 \mathrm{O} 2)$, and

55 hydroxyl radical $(\mathrm{HO} \bullet)$, are endogenously produced in cells under aerobic conditions during the autooxidation of redox enzymes. ROS play an indispensable physiological role; however, their effects oppose one another as they can both promote and prevent cell death, inflammation, or aging.1-3

$\mathrm{O} 2 \cdot-$ and $\mathrm{H} 2 \mathrm{O} 2$ are produced from the one- and two-electron reduction of molecular oxygen $(\mathrm{O} 2)$, respectively. These two oxidants react rapidly with vulnerable targets; therefore, cells are loaded with high amounts of very efficient ROS scavengers, as, for example, catalase, peroxidases ( $\mathrm{H} 2 \mathrm{O} 2$ scavengers), or superoxide dismutases ( $\mathrm{O} 2 \bullet-$ scavengers). Consequently, a balance between the intracellular $\mathrm{O} 2 \cdot-$ and $\mathrm{H} 2 \mathrm{O} 2$ production and their scavenger-mediated decomposition keeps these two oxidants' concentration in steady-state. Whereas $\mathrm{O} 2 \cdot-$ (small but charged) is not able to cross membranes, $\mathrm{H} 2 \mathrm{O} 2$ (small and uncharged) crosses membranes at a moderate efficiency, making cells sensitive to the extracellular $\mathrm{H} 2 \mathrm{O} 2$ concentration. Both $\mathrm{O} 2 \cdot-$ and $\mathrm{H} 2 \mathrm{O} 2$ are able to deteriorate the $\mathrm{Fe} 4 \mathrm{~S} 4$ clusters found in dehydratase enzymes, and, in the case of $\mathrm{H} 2 \mathrm{O} 2$, this reaction leads to the formation of the hydroxyl radical $(\mathrm{HO} \bullet)$, a process known as the Fenton reaction. $4 \mathrm{HO} \bullet$ is an extremely powerful oxidant that, for instance, is responsible for direct DNA damage (since neither $\mathrm{H} 2 \mathrm{O} 2$ nor $\mathrm{O} 2$ - - are able to damage DNA directly).2

As with any signaling mechanism, ROS can become cytotoxic if found in high concentrations or in the wrong place. The phenomenon of ROS overproduction, which contributes to oxidative stress, has been found in a great number of pathologies5-8 such as cancer, multiple sclerosis, Alzheimer's, or Parkinson diseases. Nevertheless, the role of ROS in such diseases is sometimes controversial since they may present various effects at the same time. For example, the production of ROS on tumors can range from tumor-production effects to tumor-destroying effects. In fact, some anticancer agents induce apoptosis, promoting the production of ROS, which contributes both to their efficacy and to their toxicity 3,9 (damaging tumor cells and noncancerous cells, which may cause sideeffects).

Owing to the harmful properties of ROS, antioxidant therapies have been considered for a wide variety of disorders associated with oxidative stress, which have shown promising in vivo results.10-13 Unfortunately, clinical trials to test the effect of antioxidant therapies are limited and have presented disappointing results in lots of cases. Nevertheless, the use of improved antioxidant therapies is still considered nowadays in particular cases where the oxidative stress is shown in earlier stages before the development of severe clinical manifestations, such as in children with $\alpha-1$ antitrypsin deficiency (characterized by $\mathrm{H} 2 \mathrm{O} 2$ accumulation due to the lack of catalase activity).14 Antioxidant therapy in combination with conventional therapies is also considered for diseases in which ROS play an important role in neuron-degeneration such as multiple sclerosis,15,16 Alzheimer's, 17 or Parkinson's 18 syndromes. In these cases, the chosen antioxidants should be able to penetrate the blood-brain barrier, which is the major obstacle that reduces the efficacy of many agents. 15 Targeting antioxidants to the desired position opens a new challenge in molecular recognition, as oxidative stress is produced locally or is notably harmful for the most vulnerable targets. For instance, mitochondrially targeted antioxidants could effectively reduce oxidative stress in asthma.19 Similarly, neonatal brain injury could be diminished or prevented by using antioxidants able to cross both the placenta and the blood-brain barrier.20

Within all antioxidants, catalases (CATs) are the enzymes that perform the decomposition of $\mathrm{H} 2 \mathrm{O} 2$ into $\mathrm{H} 2 \mathrm{O}$ and $\mathrm{O} 2$. In particular, Mn-CATs are found in some lactic acid bacteria. The active site of this type of CATs comprises a dinuclear Mn unit with oxo and carboxylate bridges, in which the oxidation states in the Mn2 pair alternate between (II,II) and (III,III).21 Efforts to mimic the active site and the catalytic performance of this enzyme have been performed. A large number of functional models of the Mn-CAT 
99 were summarized in 2012 by Signorella and Hureau.22 More recently, mononuclear MnIII porphyrin, 100 Schiff-base, and salen complexes have received much devotion23-27 and have deflected the attention 101 from MnIII2 mimics, reducing the emergence of this latter type.28 Moreover, dinuclear models with the 102 required stability and activity in physiological conditions have not been reported so far. The insertion of 103 Mn-CAT model compounds in porous solids offers the possibility of mimicking different properties 104 found in the native catalytic site, such as hydrophobicity and confinement.29-32 Indeed, the 105 encapsulation of antioxidants into nanocarriers could provide not only an improvement of stability but 106 also a higher therapy efficiency.33 Among inorganic-based materials, mesoporous silicas have attracted 107 much attention because of their biocompatibility at practical concentrations and their ability to protect 108 pharmaceutical principles from premature release or undesired degradation in living systems, acting as 109 an effective drug delivery system. Moreover, the versatile control over the internal and external surface 110 functionalization is advantageous for the adaptability to any guest environment 34

111 With this frame, we present here the synthesis of two new model compounds of the Mn-CAT's active 112 site with formula $[\{\mathrm{MnIII}(\mathrm{bpy})(\mathrm{H} 2 \mathrm{O})\}(\mu-2-\mathrm{MeOC} 6 \mathrm{H} 4 \mathrm{CO} 2) 2(\mu-\mathrm{O})\{\mathrm{MnIII}(\mathrm{bpy})-(\mathrm{X})\}] \mathrm{X}$, where $\mathrm{X}=$ $113 \mathrm{NO} 3$ (1) and $\mathrm{ClO} 4$ (2) and bpy $=2,2^{\prime}$ - bipyridine, and their characterization with single-crystal X-ray 114 diffraction. This kind of compounds is interesting from the magnetic point of view due to the effect of 115 the structural parameters on the type and intensity of the magnetic interaction; as we have reported previously, these systems could show different ground-spin state $(S=0$ or $S=4) .35-37$ In this work we analyze the magnetic interaction and the influence of the anisotropy in the magnetic behavior. Moreover, we report here the catalase activity of these compounds.

119 With the aim to mimic the cavity of the Mn-CAT enzyme, the two coordination compounds 1 and 2 120 were inserted in the nanochannels of mesoporous silica (MCM-41 type), and the resulting materials 121 [Mn2O]@SiO2 were characterized. The catalase activity of this new material is compared with that 122 shown by 1 and 2 to eventually evidence the advantages of the latter over the former. The reactivity is run in a mixture of acetonitrile-water and pure water. 
Synthesis of the Manganese(III) Compounds. All manipulations were performed at room temperature under aerobic conditions. Reagents and solvents were obtained from commercial sources and used without further purification. $\mathrm{NBu} 4 \mathrm{MnO} 4$ was prepared as described in the literature.38 Caution! Perchlorate salts of compounds containing organic ligands are potentially explosive. Only small quantities should be prepared.

$[\{\mathrm{Mn}(\mathrm{bpy})(\mathrm{H} 2 \mathrm{O})\}(\mu-2-\mathrm{MeOC} 6 \mathrm{H} 4 \mathrm{CO} 2) 2(\mu-\mathrm{O})\{\mathrm{Mn}(\mathrm{bpy})(\mathrm{NO} 3)\}] \mathrm{NO} 3$ (1). 2-MeOC6H4COOH $(0.24 \mathrm{~g}$, $1.6 \mathrm{mmol})$, previously dissolved in acetonitrile, was added to a solution of $\mathrm{Mn}(\mathrm{NO} 3) \cdot 4 \mathrm{H} 2 \mathrm{O}(0.32 \mathrm{~g}$, $1.28 \mathrm{mmol})$. An acetonitrile solution of NBu4MnO4 $(0.12 \mathrm{~g}, 0.32 \mathrm{mmol})$ was added to the previous mixture in small portions during 1-2 min, while, almost simultaneously, $10 \mathrm{~mL}$ of acetonitrile solution of 2,2'- bipyridine (bpy; $0.25 \mathrm{~g}, 1.6 \mathrm{mmol}$ ) was added, also in small portions. The resulting black solution (total volume $\approx 60 \mathrm{~mL}$ ) was stirred for $15 \mathrm{~min}$ and shortly afterward filtered to separate a dark precipitate. Dark crystals were isolated by filtration after $6 \mathrm{~d}$ of slow evaporation at room temperature, washed with ether, and dried under vacuum. Yield: $40 \%$. X-ray quality single-crystals were obtained by very slow evaporation of the mother solution after $15 \mathrm{~d}$. Anal. Calcd for C36H32Mn2N6O14-2H2O (\%): C, 47.07; H, 3.95; N, 9.15. Found (\%): C, 46.04; H, 3.88; N, 9.13. Selected IR data (cm-1): 3409 (br), $3093(\mathrm{w}), 3058(\mathrm{w}), 3031(\mathrm{w}), 2970(\mathrm{w}), 1601(\mathrm{~s}), 1565(\mathrm{~m}), 1498(\mathrm{w}), 1488(\mathrm{~m}), 1449(\mathrm{~m}), 1359$ (s), $1294(\mathrm{w}), 1276(\mathrm{w}), 1245$ (m) 1177 (w), 1162 (w), 1147 (w), 1102 (w), 1033 (m), 1021(w), 844 (w), $765(\mathrm{~s}), 729(\mathrm{~m}), 661(\mathrm{~m}), 536(\mathrm{w}), 463(\mathrm{w})$.

$[\{\mathrm{Mn}(\mathrm{bpy})(\mathrm{H} 2 \mathrm{O})\}(\mu-2-\mathrm{MeOC} 6 \mathrm{H} 4 \mathrm{CO} 2) 2(\mu-\mathrm{O})\{\mathrm{Mn}(\mathrm{bpy})(\mathrm{ClO} 4)\}] \mathrm{ClO} 4(2)$. An analogous procedure was followed as for 1, but using $\mathrm{Mn}(\mathrm{ClO} 4) 2 \cdot 6 \mathrm{H} 2 \mathrm{O}(0.46 \mathrm{~g}, 1.28 \mathrm{mmol})$ and only $30 \mathrm{~mL}$ of acetonitrile. Dark crystals were isolated after $10 \mathrm{~d}$ of slow evaporation at room temperature. Yield: $60 \%$. Very thin single crystals were obtained by leaving the solution undisturbed in the refrigerator after one month. Anal. Calcd for $\mathrm{C} 36 \mathrm{H} 32 \mathrm{Cl} 2 \mathrm{Mn} 2 \mathrm{~N} 4 \mathrm{O} 16 \cdot 0.25 \mathrm{CH} 3 \mathrm{CN}(\%)$ : C, 45.30; H, 3.35; N, 6.15; Cl, 7.33. Found (\%): C, 45.10; H, 3.35; N, 6.13; Cl, 7.33. Selected IR data (cm-1): IR (cm-1): 3419 (br), 3093 (w), $3084(\mathrm{w}), 3013$ (w), $2973(\mathrm{w}), 2839(\mathrm{w}), 1602$ (s), 1561 (s), 1497 (w), $1471(\mathrm{~m}), 1448(\mathrm{~m}), 1377$ (s), $1322(\mathrm{w}), 1280(\mathrm{w}), 1247$ (m), 1107 (s,br), 1032 (m), $848(\mathrm{w}), 762(\mathrm{~s}), 730(\mathrm{~m}), 663(\mathrm{~m}), 625(\mathrm{~m}), 573$ (w), $475(\mathrm{w}), 415(\mathrm{w})$.

Synthesis of [Mn2O]@SiO2. The manganese complex was inserted into LUS mesoporous silica29,39 by ionic exchange using a masking agent as described elsewhere.40 The mesoporous silica was prepared as explained below, following the ultrafast microwave-assisted synthesis reported by J. Chaignon et al.41

Sodium Silicate Solution. Ludox HS-40 (187 mL, $1.6 \mathrm{~mol} \mathrm{SiO} 2)$ was added to a sodium hydroxide (32 $\mathrm{g}, 0.80 \mathrm{~mol}$ ) in $800 \mathrm{~mL}$ of distilled water and then stirred at $40{ }^{\circ} \mathrm{C}$ overnight until obtaining a colorless solution.

SiO2-CTA. Cetyltrimethylammonium tosylate (CTATos; $7.84 \mathrm{~g}, 17 \mathrm{mmol}$ ) was stirred in water (284 $\mathrm{mL}$ ) at $60^{\circ} \mathrm{C}$ until its complete dissolution. Meanwhile, the sodium silicate solution previously prepared $(196 \mathrm{~mL})$ was also stirred at $60^{\circ} \mathrm{C}$ for $1 \mathrm{~h}$ and then added to the surfactant one by pouring it slowly on the edge of the recipient. After a vigorous shaking by hand, the resulting white mixture was placed in several autoclaves and heated in a Berghof speedwave oven. It provides a microwave irradiation at 2450 $\mathrm{MHz}$ with a power of $1450 \mathrm{~W}$. The experimental conditions used were: $\mathrm{T}=180^{\circ} \mathrm{C}, \operatorname{ramp}=1 \mathrm{~min}$, plateau $=9 \mathrm{~min}$ (total heating time $=10 \mathrm{~min}$ ). The autoclaves were allowed to cool at room temperature. Then, a white solid was filtered, washed with distilled water $(\sim 500 \mathrm{~mL})$, and dried at $80{ }^{\circ} \mathrm{C}$ to obtain $13.00 \mathrm{~g}$ of $\mathrm{SiO} 2-\mathrm{CTA}$. Anal. Calcd for $\mathrm{SiO} 2 \cdot 0.13 \mathrm{CTA} \cdot 0.40 \mathrm{H} 2 \mathrm{O}(\%)$ : C, 28.45; H, 6.05; N, 1.75. Found: C, 28.75; H, 5.95; N, 1.72; S, 0.00. Residual mass at $1100{ }^{\circ} \mathrm{C}(\%)$ : 55.43. SiO2-Ex. The surfactant was extracted by stirring $\mathrm{SiO} 2-\mathrm{CTA}(300 \mathrm{mg})$ and $\mathrm{HCl} 1 \mathrm{M}(0.75 \mathrm{~mL})$ in technical ethanol 
$(60 \mathrm{~mL})$ during $1 \mathrm{~h}$. Then, the solid was filtered, washed twice with technical ethanol $(20 \mathrm{~mL})$, and dried overnight at $80^{\circ} \mathrm{C}$.

SiO2-TMA. Tetramethylammonium bromide (TMABr; $7.08 \mathrm{~g}, 45 \mathrm{mmol}$ ) was stirred with ethanol 70\% $(600 \mathrm{~mL})$ at $40{ }^{\circ} \mathrm{C}$ for $1 \mathrm{~h}$. Then, $\mathrm{SiO} 2-\mathrm{CTA}(12.5 \mathrm{~g})$ was added to the previous solution, and the resulting suspension was stirred at $40{ }^{\circ} \mathrm{C}$ for $1 \mathrm{~h}$. A white solid was separated by filtration and washed twice with ethanol $70 \%(200 \mathrm{~mL})$ and acetone $(200 \mathrm{~mL})$. This procedure was repeated three times to ensure an entire exchange of the surfactant. Finally, the solid was dried at $80{ }^{\circ} \mathrm{C}$ to obtain $8.42 \mathrm{~g}$ of product. Anal. Calcd for SiO2 0.105 TMA 0.35 H2O (\%): C, 6.80; H, 2.66; N, 1.98. Found: C, 7.03; H, $2.61 ; \mathrm{N}, 1.93$. Residual mass at $1100{ }^{\circ} \mathrm{C}(\%): 81.23$.

[Mn2O]@SiO2. SiO2-TMA $(0.5 \mathrm{~g})$ was pretreated at $130^{\circ} \mathrm{C}$ under vacuum for $1 \mathrm{~h}$ and then allowed to cool to room temperature. Meanwhile, compound $1(250 \mathrm{mg}, 0.272 \mathrm{mmol})$ was stirred for $1 \mathrm{~h}$ in acetonitrile $(75 \mathrm{~mL})$. Then, the dark brown manganese solution was slowly added over SiO2-TMA and stirred for $24 \mathrm{~h}$. The resulting brown suspension was filtered, obtaining a dark brown powder and a clear brown solution. The powder was washed twice with acetonitrile $(20 \mathrm{~mL})$ and dried at $80{ }^{\circ} \mathrm{C}$ overnight to obtain $0.51 \mathrm{~g}$ of solid. Anal. Calcd for $\mathrm{SiO} 2 \cdot 0.033$ [Mn2O(2-MeOC6H4CO2)2(bpy)2] 0.005 TMA 0.35 H2O (\%): C, 15.91; H, 1.93; N, 2.10; Si, 30.80; Mn, 3.98. Found: C, 15.85; H, 1.95; N, 2.08; Si, $30.80 ; \mathrm{Mn}, 3.98 ; \mathrm{Cl}, 0.00$. Residual mass at $1100{ }^{\circ} \mathrm{C}(\%)$ : 72.04. The same procedure was performed but using compound $2(251 \mathrm{mg}, 0.272 \mathrm{mmol})$, and a solid with the same characteristics was obtained. Elemental analyses found (\%): $\mathrm{C}, 15.79 ; \mathrm{H}, 1.87 ; \mathrm{N}, 2.01 ; \mathrm{Cl}, 0.00$. Residual mass at $1100{ }^{\circ} \mathrm{C}(\%)$ : 70.84 .

Single-Crystal X-ray Crystallography. Crystallographic data collection and structure refinement details are summarized in Table 1 . The data collection for compound 1 was performed at $100 \mathrm{~K}$ on a Bruker Apex-II diffractometer with a graphite monochromatic Mo Ka radiation $(\lambda=0.71073 \AA)$. Unitcell parameters were determined from 9988 reflections $\left(2.39<\theta<25.06^{\circ}\right)$ and refined by least-squares method. Data $\left(27952\right.$ reflections) were collected $\left(2.39<\theta<25.08^{\circ}\right)$ using the $\omega$ and $\Phi$ scan method and corrected for absorption effects using multiscan method (SADABS). 42

The data collection for compound 2 was performed at $100 \mathrm{~K}$ on a D8 VENTURE diffractometer with a graphite monochromated Mo K $\alpha$ radiation $(\lambda=0.71073 \AA)$. Unit-cell parameters were determined from 983 reflections $\left(2.99<\theta<19.65^{\circ}\right)$ and refined by least-squares method. Data (4226 reflections) were collected $\left(1.15<\theta<20.81^{\circ}\right)$ using the $\omega$ and $\Phi$ scan method and corrected for absorption effects using empirical method (SADABS). 42

The structures were solved by direct methods and refined by fullmatrix least-squares using SHELXL97.43 Non-hydrogen atoms were refined anisotropically, whereas hydrogen atoms were computed and refined with isotropic thermal parameters riding on their respective carbon or oxygen atoms.

Compound $1 \cdot \mathrm{H} 2 \mathrm{O} \cdot 0.5 \mathrm{CH} 3 \mathrm{CN}$ crystallizes in monoclinic space group $\mathrm{C} 2 / \mathrm{c}$. In the asymmetric unit, only half a cationic complex [ $\{\mathrm{Mn}(\mathrm{bpy})(\mathrm{H} 2 \mathrm{O}) 0.5(\mathrm{NO} 3) 0.5\} 2(\mu-2-\mathrm{MeOC} 6 \mathrm{H} 4 \mathrm{CO} 2) 2(\mu-\mathrm{O})]+$ may be found. The other half is generated by a twofold axis. The voids between complexes are filled by one molecule of disordered nitrate ion per molecule of complex and disordered solvent (water and acetonitrile). A total of 306 parameters were refined in the final refinement on F2 using 106 restraints.

Compound $2 \cdot \mathrm{CH} 3 \mathrm{CN}$ crystallizes in monoclinic space group P21/c. The asymmetric unit consists of a cationic complex $[\{\mathrm{Mn}(\mathrm{bpy})-(\mathrm{H} 2 \mathrm{O})\}(\mu-2-\mathrm{MeOC} 6 \mathrm{H} 4 \mathrm{CO} 2) 2(\mu-\mathrm{O})\{\mathrm{Mn}(\mathrm{bpy})(\mathrm{ClO} 4)\}]+$, a perchlorate ion, and an acetonitrile molecule. A total of 562 parameters were refined in the final refinement on $\mathrm{F} 2$ using only one restraint. The isolated crystals of compound 2 were very thin ( $0.02 \mathrm{~mm}$ thickness), being poorly diffracting at high angles. Other attempts of crystallization were done, but no single crystals of better quality were obtained. Nevertheless, the absence of disorder and the simplicity of the crystal structure made us able to refine the crystal structure without any trouble. 
Physical Characterization. Chemical analyses $(\mathrm{C}, \mathrm{H}, \mathrm{N}$, and $\mathrm{Cl})$ were performed by the "Centres 219 Cientifí cs i Tecnolog ics" of the Universitat de Barcelona and by the "Servei de Microanàlisi" of the spectrometry (ICP-OES) was performed to determine Mn and Si percentages by the "Centres Cientifí cs i Tecnolog ics" of the Universitat de Barcelona from a solution of material [Mn2O]@SiO2 ( 20 mg) pretreated at $90{ }^{\circ} \mathrm{C}$ with a mixture of $\mathrm{HF}(200 \mu \mathrm{L})$ and $\mathrm{HNO} 3(1 \mathrm{~mL})$ into an autoclave. Infrared spectra were recorded on $\mathrm{KBr}$ pellets in the 4000-400 $\mathrm{cm}-1$ range with a Thermo Nicolet Avatar 330 FTIR spectrometer. Thermogravimetric analysis (TGA) was performed with a NETZSCH STA 409 PC Luxx device under aerobic conditions with a $10^{\circ} \mathrm{C} / \mathrm{min}$ temperature increase. Nitrogen sorption isotherms at $77 \mathrm{~K}$ were determined with a volume device Belsorp Marx on solids that were dried under vacuum overnight at $130{ }^{\circ} \mathrm{C}$ (samples $\mathrm{SiO} 2-\mathrm{Ex}$ and $\mathrm{SiO} 2-\mathrm{TMA}$ ) or at $80^{\circ} \mathrm{C}$ (samples [Mn2O]@SiO2, [Mn2O]@SiO2 \#A, [Mn2O]@SiO2 \#W, and [Mn2O]@SiO2 \#M). Low-angle X-ray powder diffraction (XRD) was performed using a Bruker (Siemens) D5005 diffractometer with $\mathrm{Cu} \mathrm{K \alpha}$ monochromatic radiation. Transmission electron microscopy (TEM) analysis was performed with a TOPCON Em-002b and operated at $120 \mathrm{kV}$, dispersing material [Mn2O]@SiO2 in ethanol and depositing it on a Holey carbon 300 mesh copper grid. The ionic conductivity $(\Lambda)$ measurements were made on a $0.8 \mathrm{mM}$ acetonitrile solution of compound 1 and 2 using a CDC401 electrode. Magnetic susceptibility $(\chi \mathrm{M})$ measurements $(2-300 \mathrm{~K})$ were performed in a Quantum Design MPMS XL5 SQUID Magnometer at the Unitat de Mesures Magnètiques of the University of Barcelona. Two different magnetic fields were used for the susceptibility measurements, $0.02 \mathrm{~T}(2-29 \mathrm{~K})$ and $0.3 \mathrm{~T}(2-300 \mathrm{~K})$, with imposable graphs. Magnetization isotherms measurements were made in the range $1.8-6.8 \mathrm{~K}$ and at six different magnetic fields $(0.5,1.0,2.0,3.0,4.0,5.0 \mathrm{~T})$. Pascal's constants were used to estimate the diamagnetic corrections for compounds 1 and 2 and material [Mn2O] @ SiO2. The fit was performed by minimizing functions RSUS $=\Sigma[(\chi \mathrm{MT}) \exp -(\chi \mathrm{MT}) \mathrm{calcd}] 2 / \Sigma[(\chi \mathrm{MT}) \exp ] 2$ and $\mathrm{RMAG}=\Sigma[(\mathrm{M} / \mathrm{N} \mu \beta) \exp -$ $(\mathrm{M} / \mathrm{N} \mu \beta)$ calcd $] 2 / \Sigma[(\mathrm{M} / \mathrm{N} \mu \beta) \exp ] 2$. Electron paramagnetic resonance (EPR) spectra were recorded at Xband $(9.4 \mathrm{GHz})$ frequency using a Bruker ESP-300E spectrometer, from room temperature to $20 \mathrm{~K}$ at the Unitat de Mesures Magnètiques (Universitat de Barcelona).

X-ray Absorption Spectroscopy. X-ray absorption near edge structure (XANES) of well-pounded microcrystalline powders of homogeneous thickness and calculated weight samples of compound 1 and material[Mn2O]@SiO2 were collected at room temperature at the synchrotron ALBA in Barcelona (Spain) on the BL22 (CLÆSS) beamline. The measurements were performed at the Mn K-edge in the transmission mode. The experiments were calibrated by verifying that the first inflection point in all manganese foil spectra recorded together with XANES spectra of the compounds was $6539 \mathrm{eV}$.

X-ray Photoelectron Spectroscopy. XPS experiments were performed in a PHI 5500 Multitechnique System (from Physical Electronics) with a monochromatic X-ray source (Al Ka line of $1486.6 \mathrm{eV}$ energy and $350 \mathrm{~W}$ ), placed perpendicular to the analyzer axis and calibrated using the $3 \mathrm{~d} 5 / 2$ line of $\mathrm{Ag}$ with a full width at half-maximum of $0.8 \mathrm{eV}$. The analyzed area was a circle of $0.8 \mathrm{~mm}$ diameter, and the selected resolution for the spectra was $187.85 \mathrm{eV}$ of pass energy and 0.8 electronvolts per step for the general spectra and $23.5 \mathrm{eV}$ of pass energy and 0.1 electronvolts per step for the spectra of the different elements. A low-energy electron gun (less than $10 \mathrm{eV}$ ) was used to discharge the surface when necessary. All measurements were made in an ultrahigh vacuum chamber pressure between $5 \times 10-9$ and $2 \times 10-8$ Torr. Binding energies were further referenced to the Csp2 peak at $284.6 \mathrm{eV}$.

Catalase Activity. The study of the catalase activity ( $\mathrm{H} 2 \mathrm{O} 2$ decomposition into $\mathrm{H} 2 \mathrm{O}$ and $\mathrm{O} 2$ ) was performed at $25^{\circ} \mathrm{C}$ by volumetric determination of the oxygen evolved with a gas-volumetric buret (precision of $0.1 \mathrm{~mL}$ ). A $32 \% \mathrm{H} 2 \mathrm{O} 2$ aqueous solution $(0.6 \mathrm{~mL})$ was added to closed vessels containing acetonitrile solutions or suspensions of compounds 1 or 2 or material [Mn2O]@SiO2 $(5 \mathrm{~mL}, 0.8 \mathrm{mM}$ referred to $\mathrm{Mn} 2$ unit), and the oxygen evolved was volumetrically measured. It is worth emphasizing that the catalase activity was studied in a $\mathrm{CH} 3 \mathrm{CN}-\mathrm{H} 2 \mathrm{O} 9: 1(\mathrm{v} / \mathrm{v})(5 \mathrm{~mL}$ of $\mathrm{CH} 3 \mathrm{CN}$ with the complex or the material and $0.6 \mathrm{~mL}$ of $\mathrm{H} 2 \mathrm{O} 2$ aqueous solution). The same procedure was repeated with the three 
systems (compounds 1 or 2 or material [Mn2O]@SiO2) using pure water as solvent instead of $\mathrm{CH} 3 \mathrm{CN}$.

268 Blank experiments performed without the catalyst (in both solvents) showed a negligible

269 disproportionation of $\mathrm{H} 2 \mathrm{O} 2$. The catalytic activity of $\mathrm{Mn}(\mathrm{NO} 3) 2$ and $\mathrm{MnO} 2$ toward $\mathrm{H} 2 \mathrm{O} 2$ disproportion

270 was tested under the same conditions as those used for 1 and 2 with $\mathrm{H} 2 \mathrm{O} 2(0.6 \mathrm{~mL})$ at $32 \%$ and a 1.6

$271 \mathrm{mM}$ acetonitrile solution $(5 \mathrm{~mL})$, equivalent to $[\mathrm{Mn} 2]=0.8 \mathrm{mM}$.

272 The $\mathrm{pH}$ measurements were made using a PHC10101 electrode. As the electrode was calibrated in

273 water, the $\mathrm{pH}$ measured in $\mathrm{CH} 3 \mathrm{CN}-\mathrm{H} 2 \mathrm{O} 9: 1(\mathrm{v} / \mathrm{v})(\mathrm{w} \mathrm{s} \mathrm{pH})$ was converted to s s pH (pH measured in

$274 \mathrm{CH} 3 \mathrm{CN}-\mathrm{H} 2 \mathrm{O}$ with electrodes calibrated in the same mixture) using the $\delta$ conversion parameter as

275 described by L. G. Gagliardi et al.44 The following equation was used: s s pH =w s pH $-\delta$, where $\delta=$

$276-1.61$ at $20^{\circ} \mathrm{C}$. The $\mathrm{pH}$ values given in this work correspond to $\mathrm{s} \mathrm{s} \mathrm{pH}$.

277 The pH-dependence study in the catalase activity was performed for compound 2 . The evolution of

278 oxygen was measured at different $\mathrm{pH}$ values using the same method and under the same conditions.

279 Et3N 99\% was used to increase the initial $\mathrm{pH}$ of the reaction media, yielding s s pH $=7.3,9.8,10.7$,

28011.8 , and 12.0, for Et3N concentrations of 1.3, 2.5, 3.8, 12.6, and $19.0 \mathrm{mM}$, respectively.

281 Material [Mn2O]@SiO2 (22 mg) was dispersed in CH3CN $(10 \mathrm{~mL})$, leading to [MnIII 2] = $0.8 \mathrm{mM}$.

282 Then, $\mathrm{H} 2 \mathrm{O} 232 \%(1.2 \mathrm{~mL})$ was added $([\mathrm{H} 2 \mathrm{O} 2] 0=1.05 \mathrm{M})$. Several fractions (of $\sim 0.6 \mathrm{~mL})$ of this

283 suspension were filtered at 30,90,230, and $600 \mathrm{~s}$ and $2 \mathrm{~h}$ after the addition of $\mathrm{H} 2 \mathrm{O} 2$. Then, EPR spectra

284 of the filtered solutions were recorded at room temperature. The EPR calibration was performed using

285 manganese(II) perchlorate $([\mathrm{MnII}]=0.044-1.45 \mathrm{mM})$.

286 The solid separated at $90 \mathrm{~s}$ after the addition of $\mathrm{H} 2 \mathrm{O} 2$ in the previous experiment was washed as soon as

287 possible with $\mathrm{CH} 3 \mathrm{CN}(20 \mathrm{~mL})$ and analyzed by EPR and XPS.

288 Postcatalysis Products. [Mn2O]@SiO2 \#A. [Mn2O]@SiO2 (100 mg) was stirred in acetonitrile (63

$289 \mathrm{~mL}$ ) for 1 or $2 \mathrm{~min}$. Then, a $32 \% \mathrm{H} 2 \mathrm{O} 2$ aqueous solution $(7.5 \mathrm{~mL})$ was added, causing immediate

290 vigorous evolution of $\mathrm{O} 2$. After $2 \mathrm{~h}$, the brown solid was separated by filtration and dried overnight at

$29180{ }^{\circ} \mathrm{C}$.

292 [Mn2O]@SiO2 \#W. An analogous procedure was followed as for [Mn2O]@SiO2 \#A, but using distilled 293 water instead of acetonitrile.

294 Stability in Water. [Mn2O]@SiO2 \#M. [Mn2O]@SiO2 (24 mg) was stirred in H2O (15 mL) for 2 h. 295 The brown solid was separated by filtration, washed with $\mathrm{H} 2 \mathrm{O}(20 \mathrm{~mL})$, and dried overnight at $80{ }^{\circ} \mathrm{C}$. 
Synthesis of Mn(III) Compounds: [\{Mn(bpy)(H2O)\}( $\mu-2-M e O C 6 H 4 C O 2) 2(\mu-O)\{M n(b p y)(X)\}] X$. Two binuclear $\mathrm{Mn}$ (III) compounds were obtained from the comproportionation reaction between MnX2 $(\mathrm{X}=\mathrm{NO} 3$ or $\mathrm{ClO} 4)$ and $\mathrm{NBu} 4 \mathrm{MnO} 4$ in the presence of 2-MeOC6H4COOH and 2,2'-bipyridine, which leads to compounds with general formula $[\{\mathrm{Mn}(\mathrm{bpy})-(\mathrm{H} 2 \mathrm{O})\}(\mu-2-\mathrm{MeOC} 6 \mathrm{H} 4 \mathrm{CO} 2) 2(\mu-$ $\mathrm{O})\{\mathrm{Mn}(\mathrm{bpy})(\mathrm{X})\}] \mathrm{X}$. The stoichiometry of this reaction is

IR spectra of these compounds show two characteristic bands at $\sim 1560$ and $1365 \mathrm{~cm}-1$, corresponding to the asymmetric and symmetric vibrations of the carboxylate groups, respectively. The bands centered at $\sim 1600,1498,1480$, and $1450 \mathrm{~cm}-1$ are assigned to the bipyridine. The $\mathrm{Mn}-\mathrm{O}-\mathrm{Mn}$ group displays a moderate band at $\sim 730 \mathrm{~cm}-1$. The spectrum of compound 1 exhibits an intense band at $1352 \mathrm{~cm}-1$ corresponding to the nitrate anion, which overlaps the vs(COO). In the spectrum of compound 2 , an intense band at $1120 \mathrm{~cm}-1$ and a moderate band at $623 \mathrm{~cm}-1$ are observed, being assigned to the perchlorate anion.

Description of the Structures. Figures 1 and 2 show the crystal structures of 1 and 2, respectively. As can be seen, both compounds display similar structures. The Mn(III) ions exhibit a distorted octahedral

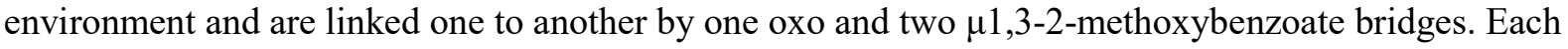
manganese ion is bound to a 2,2'-bipyridine ligand. The hexacoordination of each $\mathrm{Mn}$ ion is completed by a monodentate ligand.

The structural parameters of compounds 1 and 2 are in agreement with those reported for compounds with the same $[\mathrm{Mn} 2(\mu-\mathrm{O})(\mu-2-\mathrm{RC} 6 \mathrm{H} 4 \mathrm{CO} 2) 2] 2+$ core.35-37 Selected interatomic distances are listed in Table 2 and Table 3. The $\mathrm{Mn} \cdots \mathrm{Mn}$ distance is $\sim 3.15 \AA$, and the $\mathrm{Mn}-\mathrm{O}-\mathrm{Mn}$ angle is $\sim 123^{\circ}$. The $\mathrm{Mn}-\mathrm{O}$ bond distances of the oxo bridges are $\sim 1.78 \AA$, and the $\mathrm{Mn}-\mathrm{N}$ distances are $\sim 2.06 \AA$. The $\mathrm{Mn}-\mathrm{O}$ bond lengths of the monodentate ligands are the largest ones in the first coordination sphere, being in the range of 2.17-2.38 $\AA$, depending on the monodentate ligand. The carboxylate ligands are coordinated in a syn-syn mode. One of the oxygen atoms is placed trans to the monodentate ligand, with $\mathrm{Mn}-\mathrm{O}$ distances of $\sim 2.16 \AA$, whereas the other oxygen atom is trans to a nitrogen atom of the bpy ligand, with a shorter Mn-O distance $(\sim 1.96 \AA)$.

\section{$[\{\mathrm{Mn}(\mathrm{bpy})(\mathrm{H2O})\}(\mu-2-\mathrm{MeOC} 6 \mathrm{H} 4 \mathrm{CO} 2) 2(\mu-\mathrm{O})\{\mathrm{Mn}(\mathrm{bpy})-(\mathrm{NO})\}] \mathrm{NO3} \cdot \mathrm{H2O} \cdot \mathbf{0 . 5 C H 3 C N}$}

$(\mathbf{1} \cdot \mathbf{H 2 O} \cdot \mathbf{0 . 5 C H 3 C N})$. The crystal structure of compound 1 consists of a cationic complex, a nitrate ion, and disordered solvent. The structure of its cationic complex is shown in Figure 1. The Mn ions display an elongated coordination environment toward the monodentate ligand direction due to the Jahn-Teller effect. The relative orientation of the manganese octahedra is far from being perpendicular, with an O5-Mn1-Mn1'-O6' torsion angle of $78.1^{\circ}$. The aromatic ring and the carboxylate group of the 2methoxybenzoate ligand are not coplanar with respect to an $\mathrm{O} 3-\mathrm{C} 11-\mathrm{C} 12-\mathrm{C} 13$ torsion angle of $36.2^{\circ}$.

The monodentate ligands of $\mathrm{Mn}(\mathrm{III})$ ions are disordered, being $\mathrm{H} 2 \mathrm{O}$ or NO3-, both found with $50 \%$ occupancy. Therefore, the two $\mathrm{Mn}$ (III) ions that form the complex are crystallographically equivalent. Each binuclear entity is connected to the neighbor through hydrogen bonds between a $\mathrm{H} 2 \mathrm{O}$ molecule and a NO3 - ion (Figure S1). This interaction is extended along a longitudinal axis, resulting in a monodimensional supramolecular structure, where the position of the $\mathrm{H} 2 \mathrm{O}$ molecule and the NO3 
- ion within each aforementioned couple is statistically dictated (Figure S1). Different longitudinal organizations are aligned in a zigzag layer where every chain is antiparallel to the previous one (Figure S2). A paralleldisplaced $\pi-\pi$ interaction may be found between bipyridine ligands of adjacent chains (Figure S1). Finally, the resulting layers are antiparallel stacked, giving place to channels that are filled with anion and solvent molecules, both of them highly disordered (Figure S2).

[\{Mn(bpy)(H2O)\}( $\mu-2-M e O C 6 H 4 C O 2) 2(\mu-O)\{\mathrm{Mn}($ bpy $)-(\mathrm{ClO} 4)\}] \mathrm{ClO} 4 \cdot \mathrm{CH} 3 \mathrm{CN}(2 \cdot \mathrm{CH} 3 \mathrm{CN})$. The crystal structure of compound 2 consists of a cationic complex, a perchlorate ion, and an acetonitrile molecule. The structure of its cationic complex is shown in Figure 2. In this case, the two Mn(III) ions are not equivalent, having not only slightly different structural parameters but also different monodentate ligands. These two ions also display an elongated coordination environment toward the direction of such ligand. A water molecule is coordinated to $\mathrm{Mn} 1$ atom, with a Mn1-O8 distance of $2.219 \AA$, whereas a perchlorate ion is bound to $\mathrm{Mn} 2$ atom, the $\mathrm{Mn} 2-\mathrm{O} 9$ distance being $2.300 \AA$. As may be noticed, the $\mathrm{Mn}-\mathrm{O}$ bond length is significantly larger when the $\mathrm{ClO} 4$ - ion is the monodentate ligand, as reported previously. 36 The relative orientation of the manganese octahedra is closer to being perpendicular than in compound 1 , having an $\mathrm{O} 8-\mathrm{Mn} 1 \cdots \mathrm{Mn} 2-\mathrm{O} 9$ torsion angle of $95.2^{\circ}$. The 2methoxybenzoato ligand, which is trans to the $\mathrm{ClO} 4-$ ion, is closer to planarity than the one that is trans to the $\mathrm{H} 2 \mathrm{O}$ molecule, as indicated by the $\mathrm{O} 5-\mathrm{C} 29-\mathrm{C} 30-\mathrm{C} 35$ and $\mathrm{O} 2-\mathrm{C} 21-\mathrm{C} 22-\mathrm{C} 27$ torsion angles, which are 50.3 and $8^{\circ}$, respectively.

The binuclear complexes are connected through the noncoordinated perchlorate anions, which are bound to the water ligand via hydrogen bonds, being extended as a zigzag chain (Figure S3). No interaction is found between different chains. This chainlike structure is also found in an analogous compound reported by V. Gómez et al.36

Magnetic Properties. Magnetic susceptibility $(\chi \mathrm{M})$ data were recorded for compounds 1 and 2 from 300 to $2 \mathrm{~K}$. $\chi \mathrm{MT}$ versus T plots for 1 and 2 are shown in Figure 3. The $\chi \mathrm{MT}$ values at room temperature are close to $6.0 \mathrm{~cm} 3 \cdot \mathrm{mol}-1 \cdot \mathrm{K}$, which is the expected value for two uncoupled MnIII ions. $\chi \mathrm{MT}$ remains constant until $100 \mathrm{~K}$; below this temperature it decreases to $2.2(1)$ and $3.2(2) \mathrm{cm} 3 \cdot \mathrm{mol}-1 \cdot \mathrm{K}$ at $2 \mathrm{~K}$. This behavior is indicative of a weak antiferromagnetic coupling (ground state with $\mathrm{S}=0$ ). Magnetization $(\mathrm{M})$ data were collected in the range of $1.8-6.8 \mathrm{~K}$ using six different values of the magnetic field (0.5-5.0 T), and $\mathrm{M} / \mathrm{N} \mu \beta$ versus HT plots for compound 1 and 2 are shown in Figure S4 and Figure 3 (inset), respectively. The nonsuperposition of the various iso-field lines is indicative of a significant zero field splitting (ZFS). Both plots present a similar feature, but the $\mathrm{M} / \mathrm{N} \mu \beta$ values tend to $\sim 4.2$ for compound 1 , whereas those same values tend to $\sim 5.5$ for 2 .

These compounds show an unusual behavior at low temperatures since $\chi \mathrm{MT}$ values do not tend to zero, as expected for an $\mathrm{S}=0$ ground state. To fit the whole curve, we took into account the zero-field splittings (ZFS) DMn and EMn, which are related to the axial and rhombic anisotropy of the MnIII octahedra, respectively. This effect splits the S states into the MS components. The resulting separation and organization of these MS states (DS and ES) depend on the magnitudes, signs, and directionalities of DMn and EMn.45 In the case of a weak antiferromagnetic system like ours, the excited states $\mathrm{S}=1$ and $S=2$ are populated at low temperature, and the states $|1, \pm 1\rangle,|2, \pm 2\rangle$, and $|2, \pm 1\rangle$ could be more relevant than the respective states $|1,0\rangle$ and $|2,0\rangle$ for negative values of $\mathrm{DS}=1$ and $\mathrm{DS}=2$. This fact could explain the deviation of the $\chi \mathrm{MT}$ plot in the lowtemperature range.

Therefore, $\chi \mathrm{MT}$ versus $\mathrm{T}$ and $\mathrm{M} / \mathrm{N} \mu \beta$ versus $\mathrm{HT}$ data were fitted simultaneously using the PHI program $(\mathrm{H}=-2 \mathrm{JS} 1 \mathrm{~S} 2), 46$ considering the ZFS of manganese(III) ions (DMn and EMn) and a relative orientation of the Jahn-Teller axes of $90^{\circ}$. For compound 1, the best fit corresponds to $g=2.01,2 \mathrm{~J}=$ $-2.2 \mathrm{~cm}-1, \mathrm{DMn}=-4.6 \mathrm{~cm}-1$, and EMn (kept constant $)=1.0 \mathrm{~cm}-1$ with RSUS $=5.5 \times 10-5$ and $\mathrm{RMAG}=2.9 \times 10-3$. The $\mathrm{EMn} / \mathrm{DMn}$ ratio is $\sim 0.2$, in agreement with the rhombic distortion of the MnIII octahedra.47,48 For 2, the best fit corresponds to $\mathrm{g}=2.01,2 \mathrm{~J}=-0.7 \mathrm{~cm}-1$, and $\mathrm{DMn}=-3.0$ $\mathrm{cm}-1$, with RSUS $=9.0 \times 10-5$ and RMAG $=1.1 \times 10-3$ (see definition of RSUS and RMAG in 
Experimental Section). In this case, considering EMn was unnecessary to achieve a good fit of the could be rationalized with their structural parameters (elongation parameter $\lambda$ and the relative orientation of the octahedra $\tau$ ) as it was previously reported by V. Gómez et al.36 As commented above, compound 2 displays a greater elongation in the direction of the monodentate ligand (with $\lambda>2$ ) than 1 (with $\lambda<$ 2 ); thus, a more antiferromagnetic interaction was expected for 2 . However, the magnetic interaction for 2 is very weak, and the one for 1 is more antiferromagnetic than the expected considering only the distortion around the $\mathrm{Mn}(\mathrm{III})$ ions. This behavior could be explained with the relative disposition of the octahedra being more antiferromagnetic the lower the $\tau$ angle is. Indeed, 1 has a relatively high $\tau$ angle (O8-Mn1 $\cdots \mathrm{Mn} 2-\mathrm{O} 9$ angle of $95.2^{\circ}$ ), whereas 2 has the lowest $\tau$ angle found so far for this kind of compound $\left(\mathrm{O} 5-\mathrm{Mn} 1 \cdots \mathrm{Mn} 1^{\prime}-\mathrm{O}^{\prime}\right.$ angle of $\left.78.1^{\circ}\right)$. So, the magnetic properties of these compounds are in agreement with the magnetostructural correlations reported previously.36 The values obtained for DMn are also consistent for MnIII ions with elongated octahedral geometry, which is expected to be moderate (between -2.3 and $-4.5 \mathrm{~cm}-1$ ) and negative. $47-50$

In conclusion, compounds 1 and 2 present moderate DMn values, and because of their weak magnetic interactions and low $|\mathrm{J}|$ values, the anisotropy of MnIII ions is more important than expected for antiferromagnetic compounds. Therefore, the MS $\neq 0$ states are relevant due to the sign of DMn and the relative orientation of the Jahn-Teller axes, affecting the shape of $\chi \mathrm{MT}$ versus T plot.

Insertion of Mn(III) Compounds into Mesoporous Silica: [Mn2O]@SiO2. Synthesis Strategy. Cationic complexes of compounds 1 and 2 were inserted into the nanopores of mesoporous silica by ionic exchange.40 A step-by-step procedure to obtain material [Mn2O]@SiO2 is shown in Figure 4. Two-dimensional (2D) hexagonal LUS silica (MCM-41 type), prepared at high temperature using CTATos as a surfactant, was chosen as a support.29-32 It possesses a large pore volume of $0.80 \pm 0.01$ $\mathrm{cm} 3 \cdot \mathrm{g}-1$ and a narrow pore size distribution (pore diameter $=3.8 \pm 0.1 \mathrm{~nm}$ ) that may be suitable for the insertion of compounds 1 and 2 , which are $\sim 1.3 \mathrm{~nm}$ wide. The cationic surfactant of the as-made silica ( $\mathrm{SiO} 2-\mathrm{CTA}$ ) was exchanged for tetramethylammonium cations (TMA + ) using the procedure described by K. Zhang et al.,40 leading to the formation of $\mathrm{SiO} 2-\mathrm{TMA}$ with molar composition $\mathrm{SiO} 2 \cdot 0.105$ TMA· $0.35 \mathrm{H} 2 \mathrm{O}$.

[Mn2O]@SiO2 was prepared from the mixture of an acetonitrile solution of compound 1 or 2 and $\mathrm{SiO} 2-\mathrm{TMA}$ at room temperature. TMA+, which is only held into the silica by electrostatic forces, is easily displaced when other positively charged species with more affinity for silica are present. The $[\mathrm{Mn} 2] 2+/ \mathrm{TMA}+$ molar ratio used was 0.5 , which corresponds to 1.0 for charge ratio.

The elemental analysis revealed that materials [Mn2O]@SiO2 obtained from 1 or 2 have the same molar composition, and their IR spectra were superimposable. The results obtained from thermogravimetric analysis as well as from N2 sorption isotherms for both materials may be considered identical (Table 4 and Figure S5), as the differences between the solids are within the experimental error. These facts prove that the counteranions have an unperceived effect and, obviously, that they remain in solution without being retained by the silica.

Morphology of the Hybrid Material. The hexagonal array of the internal pores of the material was unaltered during the insertion of the Mn complex, as shown from the XRD patterns (Figure S6; the distance between the centers of the pores (a0) being $4.8 \pm 0.1 \mathrm{~nm}$ (Table 4)). The TEM images of the hybrid material [Mn2O]@SiO2 (Figure S7) confirm the persistence of the cylinder array along the (110) plane. The low-temperature nitrogen sorption isotherms of the surfactant-extracted support, $\mathrm{SiO} 2-\mathrm{Ex}$, and the hybrid solids, SiO2-TMA and [Mn2O]@SiO2, exhibit a type IV isotherm according to the IUPAC nomenclature, without hysteresis as usually observed for MCM- 41 2D hexagonal mesoporous silica.30,51 The decrease of pore volume from 0.80 to $0.36 \mathrm{~cm} 3 \cdot \mathrm{g}-1$ after the insertion confirms the presence of the complex inside the pores. This is also consistent with the decrease of intensity of the peak (100) observed in XRD of material [Mn2O]@SiO2, since a lower intensity is expected for those 
whose contrast between silica wall and the channel atom occupancy is lower.52,53 The BET constant C of the hybrid material is much lower than that of the $\mathrm{SiO} 2-\mathrm{Ex}$ (Table 4), which indicates that the surface has become more hydrophobic. Moreover, the capillary condensation shifts to a lower range of pressures in the solid [Mn2O]@ SiO2 (Figure 5), corresponding to a pore size reduction of $\sim 0.7 \mathrm{~nm}$. It also occurs progressively in a wider range of pressures and not in a series of steps, indicating that the Mn complex was properly spread along the whole channel. In this case, the pore size distribution is broad due to the inequality and roughness of the surface caused by the Mn complex's shape, covering values between 2.8 and $3.3 \mathrm{~nm}$ according to Broekhoff and de Boer (BdB) analysis. 54

Characterization of the Mn(III) Complex Inside the Silica Support. The calculated formula from the elemental analysis for the [Mn2O]@SiO2 hybrid material is $\mathrm{SiO} 2 \cdot 0.033$ [Mn2O-

(2-MeOC6H4CO2)2(bpy)2] $\cdot 0.005$ TMA $0.35 \mathrm{H} 2 \mathrm{O}$. This metal loading corresponds to ca. $66 \%$ of the cationic exchange capacity assuming two positive charges for both 1 and 2 complexes and that both $\mathrm{X}^{-}$ ions are removed. Strikingly, the remaining quantity of TMA+ ions in the solid is much less than the $34 \%$ expected for a mere cation exchange of two TMA+ per complex as it is only $5 \%$ of the initial content of SiO2-TMA. Accordingly, the missing TMA+ is removed according to another reaction that is likely neutralization. Indeed, the acetonitrile solutions of the $\mathrm{Mn}(\mathrm{III})$ compounds contain traces of water and are acidic, allowing a partial protonation of the silanolate and the release of additional TMA+ ions. The thermogravimetric analysis (TGA) shows two main mass losses in the range of $200-400{ }^{\circ} \mathrm{C}$ that are mainly assigned to the decomposition of the Mn complex's ligands and suit perfectly with the calculated formula (see more details in Supporting Information).

The IR spectrum of [Mn2O]@SiO2 contains the vibrational fingerprints of the complexes' ligands and TMA+ ions, particularly in the window of 1700-1200 cm-1 (Figure 6). Despite a weak concentration, the narrow peak at $1488 \mathrm{~cm}-1$ typical of $\mathrm{CH} 3$ scissoring vibrational mode of the TMA+ appears in the middle of bands belonging to the ligand and attests for its presence in [Mn2O]@SiO2.40 Nearby, the bands centered at 1604, 1473, and $1442 \mathrm{~cm}-1$ are assigned to the bipyridine ligand. The weak band expected at $1496 \mathrm{~cm}-1$ is masked by the band assigned to TMA+ (see above). At 1558 and $1396 \mathrm{~cm}-1$ arise the asymmetric and symmetric vibrations of the carboxylate groups, respectively. It is worth noting that the symmetric vibration shifts from $\sim 1370$ (as observed in the IR spectra of compounds 1 and 2 ) to $1396 \mathrm{~cm}-1$ when the complexes are incorporated in the silica pores, suggesting a slight change of structural parameters upon which carboxylate bridges are participating. Nevertheless, in spite of decreasing, the $\Delta \mathrm{v}$ value $(\Delta \mathrm{v}=\mathrm{va}(\mathrm{COO})-\mathrm{vs}(\mathrm{COO}))$ is in the range found for bidentate carboxylate ligands coordinated to two metal ions in bridging mode $\mu 1,3.55$ Moreover, the absence of bands at $\sim 1700 \mathrm{~cm}-1$ excludes the presence of protonated carboxylate groups and consequently excludes the decoordination of these ligands. The broadening of the signals may be either due to distribution of slightly different species on the surface, caused by the heterogeneity of the environment,56 or due to dynamic effects. 57

To characterize the nature of the $\mathrm{Mn}(\mathrm{III})$ complex within the silica support, X-ray absorption spectroscopy (XAS) measurements of compound 1 (as model) and material [Mn2O]@SiO2 were performed. Mn K-edge XANES and the pre-edge before the main K-edge are sensitive to the oxidation state and bonding environment of manganese.58,59 Between them, the pre-edge region is much less influenced by the medium as compared to the edge jump region. 60 Compound 1 shows a pre-edge peak at $6541 \mathrm{eV}$, while for the material [Mn2O]@SiO2 two features, at 6540 and $6543 \mathrm{eV}$, could be observed (Figure S8). Moreover, for the hybrid material, the first inflection point of the Mn K-edge is shifted by $1.8 \mathrm{eV}$, in comparison to compound 1. Both factors suggest some change in the hybrid material. According to the XPS analysis and the magnetic measurements (see below), the difference between 1 and $[\mathrm{Mn} 2 \mathrm{O}] @ \mathrm{SiO} 2$ could have been promoted by the radiation. So, this technique did not allow us to obtain valuable information about the manganese complex. 
With the aim to clarify what is the oxidation state of the Mn complex inside the support, XPS measurements of compound 1 (as model) and material [Mn2O]@SiO2 were performed. The results obtained from the fit of the $\mathrm{C} 1 \mathrm{~s}$, the $\mathrm{N} 1 \mathrm{~s}$, and the Mn 3s peaks are summarized in Table S1. The $\mathrm{C} 1 \mathrm{~s}$ signals of compound 1 and material [Mn2O]@SiO2 are very similar and are distributed in three main XPS features, assigned to Csp2 $(284.6 \mathrm{eV}), \mathrm{C}-\mathrm{N}$ and C-Oether $(\sim 286 \mathrm{eV})$, and Ccarboxylate $(\sim 288$ $\mathrm{eV}$ ) (Figure S9).61,62 Moreover, the $\mathrm{C} / \mathrm{Mn} 2$ and N/Mn2 ratios (being 35 and 4, respectively) are consistent with the existence of the [MnIII 2O(2-MeOC6H4CO2)2(bpy)2]2+ unit in material [Mn2O]@SiO2.

Figure 7 shows the Mn 3s spectra for 1 and material [Mn2O]@SiO2. The Mn 3s doublet splitting $(\Delta \mathrm{Mn}$ $3 \mathrm{~s}$ ) provides a reliable way of determining the oxidation state of manganese, being smaller for higher oxidation state. 63 Both solids display $\Delta \mathrm{Mn} 3 \mathrm{~s}$ equal to $5.6 \mathrm{eV}$ (Table $\mathrm{S} 1$ ), which is in agreement with those reported by J. Nelson et al. for a series of Mn(III) complexes with carboxylate and oxo bridges64 and also with the values collected in Table S2 for compounds with different oxidation states. This fact confirms that, for material [Mn2O]@ SiO2, the oxidation state of the Mn ions is III.

The N 1s spectrum of compound 1 (shown in Figure 7) displays two main peaks, assigned to the $\mathrm{N}$ atoms of the bpy (blue peak centered at $399.6 \mathrm{eV}$ ) and to the NO3 - anions (green peak centered at $406.2 \mathrm{eV}$ ).61 As expected, the NO3 - peak is not present in the N 1s spectrum of material [Mn2O]@ $\mathrm{SiO} 2$, consistent with the absence of the counteranion in the hybrid material as explained above. Indeed, the overall N/Mn2 ratio is lower for [Mn2O]@SiO2 than for 1 and agrees with two bpy ligands for each $\mathrm{Mn} 2$ entity, in agreement with the loss of NO3 - ions during the synthesis of the $\mathrm{Mn}-\mathrm{Si}$ hybrid. Moreover, the peak around $401 \mathrm{eV}$ is now split in two components, centered at 399.3 (blue) and 402.4 $\mathrm{eV}$ (cyan). The first and more intense peak could be assigned to Nsp2 neutral atoms, 65 while the second and weaker could be attributed to some change in the coordination of one of the bpy ligands likely due to the interaction with the silica support.56,61

Magnetic measurements were also performed for material [Mn2O]@SiO2. The $\chi \mathrm{MT}$ versus T plot of this material (shown in Figure 8) indicates that there is a non-negligible interaction between the Mn ions, which strongly supports the assumption that the MnIII 2 unit is maintained in the silica pores. The $\chi \mathrm{MT}$ value at room temperature $(5.8 \mathrm{~cm} 3 \cdot \mathrm{mol}-1 \cdot \mathrm{K})$ is close to the expected value for two uncoupled $\mathrm{Mn}(\mathrm{III})$ ions. The data were fitted from 300 to $17 \mathrm{~K}$ using the PHI program (H=-2JS1S2), 46 omitting the data at low temperature $(17-2 \mathrm{~K})$ to avoid ZFS effects. The best fit corresponds to $g=1.98,2 \mathrm{~J}=$ $-1.2 \mathrm{~cm}-1$, Rsus $=3.4 \times 10-5$. The $\mathrm{J}$ value is between those found for 1 and 2 ; thus, it is also in the expected range for a [MnIII 2O(2-RC6H4COO)2]2+ subunit (between -12 and $+5 \mathrm{~cm}-1) .36$ Unfortunately, we could not fit the whole curve due to a deviation in the low-temperature range. As it was mentioned, magnetic properties of this kind of complexes are very sensitive to structural and electronic parameters.35-37 So, this deviation may be due to the existence of more than one species that could slightly differ in some structural parameters. We achieved the fitting of the whole curve by keeping constant the parameters referred to the Mn anisotropy, with very similar values to the molecular analogues (compounds 1 and 2). However, reporting this last fit would be meaningless because it involves the assumption of unknown parameters, such as DMn, EMn, and the relative orientation of the Jahn-Teller axes of the MnIII ions.

Catalase Activity. The catalyzed disproportionation reaction of $\mathrm{H} 2 \mathrm{O} 2$ to $\mathrm{H} 2 \mathrm{O}$ and $\mathrm{O} 2$ (catalase activity) was studied with the two dinuclear MnIII compounds (1 and 2) and with material [Mn2O]@SiO2, and then the results were compared.

Catalase Activity of Compounds 1 and 2. The catalytic activity of these compounds was tested by mixing a $0.8 \mathrm{mM}$ acetonitrile solution of compounds 1 or 2 and a $32 \%$ aqueous solution of $\mathrm{H} 2 \mathrm{O} 2$, with $[\mathrm{H} 2 \mathrm{O} 2] 0=1.05 \mathrm{M}$ (initial concentration of $\mathrm{H} 2 \mathrm{O} 2$ ) and $[\mathrm{H} 2 \mathrm{O} 2] 0 /[\mathrm{MnIII} 2]=1312$. Note that the resulting reaction media consists of a $\mathrm{CH} 3 \mathrm{CN}-\mathrm{H} 2 \mathrm{O} 9: 1(\mathrm{v} / \mathrm{v})$ mixture. The evolution of oxygen was monitored versus time by volumetric method and then converted to turnover number (TON), 
considering a two-step reaction that comprises the oxidation and reduction of $\mathrm{H} 2 \mathrm{O} 2$. Following this definition, a TON is equal to the decomposition of two moles of $\mathrm{H} 2 \mathrm{O} 2$ per mole of MnIII 2.

In these experiments, vigorous evolution of $\mathrm{O} 2$ was also observed after the addition of hydrogen peroxide. As shown in Table 5, compounds 1 and 2 are able to decompose a significant amount of $\mathrm{H} 2 \mathrm{O} 2$ (TON $\approx 480$ in $10 \mathrm{~min}$ ), which evidences their catalytic activity. During the first minute the TON follows an almost linear tendency with time; for time $>1 \mathrm{~min}$, the reaction slows until reaching a plateau at $\sim 10$ min (Figure 9). The activity of such compounds is of the same magnitude as some other analogues reported in the literature.66,67

The catalytic activity of $\mathrm{Mn}(\mathrm{NO} 3) 2$ and $\mathrm{MnO} 2$ toward $\mathrm{H} 2 \mathrm{O} 2$ disproportionation was also investigated under the same conditions as those used for compounds 1 and 2 . In both cases, the activity is $\sim 1$ order of magnitude smaller than the one displayed by 1 and 2 during all the experiments.

According to single-crystal XRD (explained above), the crystal structures of compounds 1 and 2 is a 1:1 electrolyte, whose cation is a monocharged complex with formula $[\{\mathrm{Mn}(\mathrm{bpy})(\mathrm{H} 2 \mathrm{O})\}(\mu-2-$ $\mathrm{MeOC} 6 \mathrm{H} 4 \mathrm{CO} 2) 2(\mu-\mathrm{O})\{\mathrm{Mn}(\mathrm{bpy})-(\mathrm{X})\}]+$ with the monodentate positions occupied by water and a molecule of counteranion (X). But these last positions are quite labile, so the substitution of the $\mathrm{X}$ ligands is expected in solution. The molar ionic conductivity $(\Lambda \mathrm{M})$ of an acetonitrile solution of compound 2 is $271 \mathrm{~S} \cdot \mathrm{cm} 2 \cdot \mathrm{mol}-1$, typical for a $2: 1$ electrolyte solution $(220-300 \mathrm{~S} \cdot \mathrm{cm} 2 \cdot \mathrm{mol}-1) .68$ This value indicates that the perchlorate anions are completely dissociated from the manganese complex. However, the $\Lambda \mathrm{M}$ of an acetonitrile solution of compound $1(106 \mathrm{~S} \cdot \mathrm{cm} 2 \cdot \mathrm{mol}-1)$ is much lower than for 2 , being close to the $1: 1$ electrolyte range (120-160 S cm2 mol-1).68 This is consistent with one of the nitrate ions interacting with the manganese coordination sphere. Nevertheless, the addition of a small amount of water to the solution of compound $1(\mathrm{CH} 3 \mathrm{CN}-\mathrm{H} 2 \mathrm{O} 9: 1(\mathrm{v} / \mathrm{v}))$ makes the $\Lambda \mathrm{M}$ increase to 189 $\mathrm{S} \cdot \mathrm{cm} 2 \cdot \mathrm{mol}-1$, which is a higher value but still much below the characteristic range for a 2:1 electrolyte solution. These facts prove that the nitrate anion tends to interact more than the perchlorate with the $\mathrm{Mn}$ complex and, even though the presence of water may weaken this interaction, nitrate anions seem to remain in contact with the complex, either via hydrogen bonds or by a genuine $\mathrm{Mn} \cdots \mathrm{ONO} 2$ interaction.

In spite of displaying very similar structures, compound $1(X=N O 3)$ is a better catalyst than $2(X=$ $\mathrm{ClO} 4)$; so, the cause of this difference may only lay on their $\mathrm{X}$ group. This fact was also reported previously by G. Fernández et al. for analogous compounds with acetate or chloroacetate bridges, where the ones with $\mathrm{X}=\mathrm{NO} 3$ are also better catalysts than the ones with $\mathrm{X}=\mathrm{ClO} 4$ even though they have the same cationic complex $(\mathrm{L}=\mathrm{H} 2 \mathrm{O} / \mathrm{H} 2 \mathrm{O}) .69$

To sum up, when 1 is in solution, nitrate ion is likely interacting with the Mn complex in acetonitrile solution, and this interaction is weakened with the presence of water. Thus, in spite of the nitrate anion being retained by the Mn complex, this could be effortlessly displaced in the presence of another group. In the case of the solid, the inner surface of material SiO2-TMA (the precursor used to form the hybrid material [Mn2O]@SiO2) is formed by silanote groups that electrostatically interact with TMA+ ions and silanol groups. The Mn complex is indeed incorporated inside the pores by ion exchange. Once the TMA+ ions are displaced by the Mn complex, the silanolate groups are free to interact with the Mn complex, this latter leaving behind the nitrate ions.

Effect of $\mathrm{pH}$ on the Catalase Activity of Compound 2. In the literature there are some antecedents of the $\mathrm{pH}$-dependent catalase activity for different kinds of Mn complexes.70,27 Taking into account this and the possibility of the silica acting as a $\mathrm{pH}$ modulator, the catalase activity of 2 was evaluated at different $\mathrm{pH}$ values. We chose the compound with $\mathrm{X}=\mathrm{ClO} 4$ (2) because this counteranion interacts less with the Mn complex in acetonitrile solution than $\mathrm{NO} 3$ - anion (as explained above), so its presence is likely more innocent.

Compound 2 yields a $\mathrm{pH}=6.0$ in $\mathrm{CH} 3 \mathrm{CN}-\mathrm{H} 2 \mathrm{O} 9: 1(\mathrm{v} / \mathrm{v})$. Hence, triethylamine was used to increase the basicity of the reaction media, with [Et3N]/[MnIII 2] ratios between 0 and $\sim 24$. Figure 10 shows the 
TON versus time at different $\mathrm{pH}$ values, and the catalytic results of this experiment are summarized in Table S3. Note that the more basic the reaction media is, the more efficient the catalyst is. Conversion close to $100 \%$ can only be reached at extremely basic $\mathrm{pH}$ values $(\mathrm{pH}>12)$.

Catalase Activity of Material [Mn2O]@SiO2. The catalytic activity toward the $\mathrm{H} 2 \mathrm{O} 2$ decomposition from an acetonitrile suspension of material [Mn2O]@SiO2 (0.8 mM based on [MnIII2]) was also tested under the same conditions as compounds 1 and 2 to lately be compared. It is necessary to point out that $\mathrm{SiO} 2-\mathrm{TMA}$ did not provoke any evolution of oxygen, which excludes any catalytic activity of the support itself for $\mathrm{H} 2 \mathrm{O} 2$ disproportionation. Looking briefly at Figure 11, one can say that the TON versus time plot of material [Mn2O]@SiO2 has the same profile as its molecular analogues, first following a linear tendency and lately reaching a plateau. Table 6 summarizes the results obtained from the catalysis. As can be seen, the hybrid material exhibits a better catalase activity than compounds 1 and 2. The suspension of the hybrid material shows a $\mathrm{pH}=8.9$, and their activity is in the middle of those displayed for compound 2 at $\mathrm{pH}=7.3$ and 9.8. This fact suggests that one of the effects for the major activity of the material in comparison to the molecular compounds is the basic media provided by the silanolate groups of the support $\leftarrow$ the $\mathrm{pKa}$ of which is $\sim 9.71,72$

A similar $\mathrm{pH}$ dependence was already reported in the literature for a mutated $\mathrm{Mn}$ catalase 73 and for some MnIII2 salen complexes28,70,27 in which the catalase activity was highly improved at high $\mathrm{pH}$ (that guarantees the integrity of the Mn2 unit) or because of the presence of an acid-base catalytic auxiliary. In our case, the silanolate moieties in the hybrid material likely act as an endogenous acid-base auxiliary that could contribute to retain the integrity of the Mn2 core, improving its activity.

Successive additions of $\mathrm{H} 2 \mathrm{O} 2$ were done to test if the catalyst retains its activity. As shown in Figure 12 , the catalyst keeps a high activity after several additions, reaching a plateau at almost the same TON after the second and third additions (green). In spite of that, the initial rate of $\mathrm{H} 2 \mathrm{O} 2$ dismutation for the second and third additions is lower than for the first one (red), which could be caused by the decrease observed in the $\mathrm{pH}$ (from 8.9 to $~ 7.5$ ).

Several EPR spectra were recorded for the solution - separating the solid - at different times, between 30 $\mathrm{s}$ and $2 \mathrm{~h}$ after the addition of $\mathrm{H} 2 \mathrm{O} 2$. Nonsignificant EPR signal was observed in none of them, indicating that the $\mathrm{Mn} 2+$ content in the solution is $<73 \mu \mathrm{M}$ (limit of detection), which corresponds to 5\% of the $\mathrm{Mn}$ in material [Mn2O]@SiO2. As the solution does not present the brown color expected for a MnIII solution, one can conclude that practically all Mn content remains inside the pores of the silica.

The isolated solid at $90 \mathrm{~s}$ after the addition of $\mathrm{H} 2 \mathrm{O} 2$ was analyzed by XPS and EPR spectroscopy. The XPS displays a Mn $3 \mathrm{~s}$ doublet splitting ( $\triangle \mathrm{Mn} 3 \mathrm{~s}$ ) of 5.6-5.7 eV, indicating that the Mn oxidation state is mainly III (Table S2). Even though the majority of the Mn oxidation state is III, the EPR spectra (Figure S10) shows six bands in the region of $\mathrm{g} \approx 2$ with a hyperfine coupling of $\sim 9 \mathrm{mT}$. This pattern could be consistent with a dinuclear $\mathrm{Mn}$ (II) complex with a weak magnetic coupling.69 No evidence of mixed valence systems (MnII-MnIII or MnIII-MnIV) was observed. These facts suggest that catalytic species involves MnII and MnIII oxidation states and that it mainly remains inside the pores. However, the XPS analysis of this sample shows a lower N/Mn2 ratio than that of the former material [Mn2O]@SiO2. This could be indicative of a partial unfastening of the bpy ligand from the solid. As it was indicated, in the hybrid material some $\mathrm{N}$ atoms of the bpy ligand could interact with the silanolate groups of the wall, suggesting a quite weak $\mathrm{Mn}-\mathrm{N}$ bond. During the catalytic process, the strength of this bond could decrease, the bpy ligand being more labile. Therefore, the partial release of the bpy from the hybrid material could probably be due to the treatment of the sample (washing and drying) before the measurements.

Catalase Activity in Aqueous Media of 1, 2, and [Mn2O]@ SiO2. In contrast to the activity in acetonitrile (see above), compounds 1 and 2 are not good catalysts in water solution, hardly 
627 decomposing $~ 5 \%$ of the [H2O2]0 in $10 \mathrm{~min}$ (Table 7). This is predictable since $\mathrm{Mn} 2$ compounds have 628 low stability in aqueous media.22

629 However, the hybrid material shows catalase activity in aqueous media. As showed in Figure 13 and 630 Table 7, material [Mn2O]@SiO2 is able to reach TON $\approx 400$ in 5 min with linear tendency. Then, it 631 approaches an asymptotic value of 514 at $10 \mathrm{~min}$. Nevertheless, the activity of this material in water is 632 lower than in acetonitrile, especially in the first minute.

633 Stability of Material [Mn2O]@SiO2. The morphology and characteristics of material [Mn2O]@SiO2 634 after the $2 \mathrm{~h}$ reactions with $\mathrm{H} 2 \mathrm{O} 2 \mathrm{in} \mathrm{CH} 3 \mathrm{CN}-\mathrm{H} 2 \mathrm{O}$ 9:1 (v/v) ([Mn2O]@SiO2 \#A) and in water 635 ([Mn2O]@SiO2 \#W) were analyzed. The results are summarized in Table 8.

636 Material [Mn2O]@SiO2 \#A preserves the mesostructure and porosity of the former material $637[\mathrm{Mn} 2 \mathrm{O}] @ \mathrm{SiO} 2$, as observed in the XRD pattern and the N2 sorption isotherms (Figure $\mathrm{S} 11$ ). 638 Nevertheless, the pore volume is higher than the one observed for [Mn2O]@SiO2, and the mass loss 639 corresponding to the Mn complex's ligands decreased, suggesting that the pores are less loaded. This 640 fact is in agreement with the XPS analysis performed on the isolated solid during the reaction (explained 641 above).

642 Contrary to the previous one, material [Mn2O]@SiO2 \#W displayed a poor XRD pattern and N2 643 sorption isotherms without a clear capillary condensation (Figure S12), meaning that the mesostructure 644 was disrupted after the reaction with $\mathrm{H} 2 \mathrm{O} 2$.

645 To know whether this fact is due to the water or the H2O2, the stability of material [Mn2O]@SiO2 was 646 also checked in water suspension. After $2 \mathrm{~h}$ of treatment, the resulting solid ([Mn2O]@SiO2 \#M) 647 displays the typical N2 sorption isotherms of a mesostructured material (Figure S13). So, the support 648 itself is not disrupted by the presence of water; but it has also a higher pore volume than its former 649 material ([Mn2O]@SiO2).

650 To summarize, the presence of water is not responsible for the damage of the mesostructure of the 651 support; this is only altered when both water and $\mathrm{H} 2 \mathrm{O} 2$ are present. In addition, the water and the 652 reaction with $\mathrm{H} 2 \mathrm{O} 2$ favor the release of part of the bpy ligands. However, the loss of loading could 653 occur during the process of isolation of the solid.

654 These facts could be attributed to the nudity of the silica's inner surface. Even though the ultrafast 655 microwave-assisted synthesis leads to highly ordered and chemically stable mesoporous silica, 41 the 656 pore surface is formed by Q3 (mainly) and Q2 silanol groups, which are sensitive to nucleophilic attacks 657 and to strong oxidants. Therefore, modification of the silica's internal surface is under progress to overcome these limitations. Hydrophobization and covering of the pore surface would hopefully limit the internal water diffusion and increase the stability of both the Mn complex and the structure of the 660 nanochannels. 
664 Two dinuclear manganese(III) compounds with formula [\{Mn(bpy)(H2O) $\}(\mu-2-\mathrm{MeOC} 6 \mathrm{H} 4 \mathrm{CO} 2) 2(\mu-$ $665 \mathrm{O})\{\mathrm{Mn}(\mathrm{bpy})-(\mathrm{X})\}] \mathrm{X}(\mathrm{X}=\mathrm{NO} 3$ or $\mathrm{ClO} 4)$ have been synthesized (only differing in the counteranion) 666 and structurally and magnetically characterized. The crystal structure reveals that the anions tend to be 667 coordinated to one manganese ion, occupying one monodentate position. The distortion of the 668 coordination octahedron of the manganese ion depends on this monodentate ligand, being more 669 elongated with $\mathrm{X}=\mathrm{ClO}$. The antiferromagnetic interaction between the $\mathrm{Mn}(\mathrm{III})$ ions is affected by the 670 structural parameters, mostly by the relative disposition of the Jahn-Teller axes. The almost orthogonal 671 disposition of these axes together with a negative value of the ZFS parameter (DMn) are relevant on the 672 magnetic behavior at low temperature. These compounds are structural and functional models of the 673 Mn-catalase, being able to catalyse the $\mathrm{H} 2 \mathrm{O} 2$ decomposition in $\mathrm{CH} 3 \mathrm{CN}-\mathrm{H} 2 \mathrm{O}$ 9:1 (v/v) solution. 674 Compound 1, with nitrate as counteranion and labile ligand, is more efficient than compound $2(\mathrm{X}=$ $675 \mathrm{ClO} 4)$.

676 The insertion of compounds 1 and 2 into mesoporous silica, by ionic exchange, leads to the same 677 material, indicating that only the cationic complex is grafted inside the support. The analysis of the new 678 material shows that the Mn complex occupies half of the available mesoporous volume within the pores 679 and that the hexagonal array was unaltered upon the insertion of the Mn complex. Moreover, a non680 negligible antiferromagnetic interaction between $\mathrm{Mn}$ (III) ions was observed, indicating that the 681 dinuclear unit is preserved inside the silica.

682 The hybrid material shows also catalase activity, and it is more efficient than the coordination 683 compounds 1 and 2 . This fact is due to the presence of silanolate groups that likely buffers a basic $\mathrm{pH}$ 684 and favors the catalyzed $\mathrm{H} 2 \mathrm{O} 2$ decomposition. According to EPR spectroscopy and XPS analysis, the 685 reaction seems to take place inside the support and that the Mn oxidation state swings between II and III. 686 The insertion of the coordination compound inside the mesoporous silica provides a good way to protect 687 the catalytic center from the external media and opens a new approach to work with manganese 688 compounds in aqueous media, paving the way toward the application of these active antioxidant species 689 at physiological conditions. 


\section{AUTHOR INFORMATION}

692

\section{Corresponding Authors}

694 *E-mail: luis.escrichetur@gmail.com.

695 *E-mail: belen.albela@ens-lyon.fr.

696

$697 \quad$ Notes

698 The authors declare no competing financial interest

699

700

701

702 


\section{ACKNOWLEDGEMENTS}

705 This work was supported by the Ministerio de Ciencia e Innovación of Spain (Project Nos. CTQ2012-

70630662 and CTQ2010-15364), the Agència de Gestió d'Ajuts Universitaris i de Recerca (AGAUR) of la

707 Generalitat de Catalunya (Project No. 2009-SGR1454), the Region Rhône-Alpes of France (Project No.

708 COOPERA-C-1349S81), the Generalitat Valenciana (Project No. ISIC2012/002), and the Consorcio

709 para la Construcción, Equipamiento y Explotación del Laboratorio de Luz Sincrotrón (CELLS; Project

710 No. 2012100444-3). L.E. thanks the Univ. of Barcelona for the APIF fellowship and the C-MIRA

711 program of the Region Rhône-Alpes in France for the financial support to the collaboration between the

712 Univ. of Barcelona (Spain) and the École Normale Supérieure de Lyon (France). XAS experiments were

713 performed at BL22 (CLÆSS) beamline at ALBA Synchrotron Light Facility with the collaboration of

714 ALBA staff. In particular, we thank C. Marini for his help in the normalization of spectra. We are also

715 very thankful to F. Vadcard, S. Speed, and N. Calin for their contribution to TEM, the resolution of

716 crystal structures, and powder XRD measurements, respectively. Finally, we show L. Calvo and N.

717 Iranzo gratitude for their help with the treatment and interpretation of the XPS data. 
724

725

726

727

728

729

730

731

732

733

734

735

736

737

738

739

740

741

742

743

744

745

746

747

748

749

750

751

752

753

754

755

\section{REFERENCES}

(1) Lippard, S. J.; Berg, J. M. Principles of Bioinorganic Chemistry; University Science Books, 1994.

(2) Imlay, J. A. Nat. Rev. Microbiol. 2013, 11, 443-454.

(3) Nathan, C.; Cunningham-Bussel, A. Nat. Rev. Immunol. 2013, 13, 349-361.

(4) Walling, C. Acc. Chem. Res. 1975, 8, 125-131.

(5) Costa, V.; Moradas-Ferreira, P. Mol. Aspects Med. 2001, 22, 217-246.

(6) Sayre, L. M.; Perry, G.; Smith, M. A. Chem. Res. Toxicol. 2008, 21, 172-188.

(7) Warner, D. S.; Sheng, H.; Batinić-Haberle, I. J. Exp. Biol. 2004, 207, 3221-3231.

(8) Valko, M.; Leibfritz, D.; Moncol, J.; Cronin, M. T. D.; Mazur, M.; Telser, J. Int. J. Biochem. Cell Biol. 2007, 39, 44-84.

(9) Watson, J. Open Biol. 2013, 3, 120144.

(10) Day, B. J. Biochem. Pharmacol. 2009, 77, 285-296.

(11) Day, B. J. Drug Discovery Today 2004, 9, 557-566.

(12) Batinić-Haberle, I.; Rebouças, J. S.; Spasojević, I. Antioxid. Redox Signaling 2010, 13, 877-918.

(13) Day, B. J. Antioxid. Redox Signaling 2007, 10, 355-370.

(14) Escribano, A.; Amor, M.; Pastor, S.; Castillo, S.; Sanz, F.; Codoñer-Franch, P.; Dasí, F. Thorax $2015,70,82-83$.

(15) Offen, D.; Melamed, E.; Gilgun-Sherki, Y. J. Neurol. 2004, 251, 261-268.

(16) Karlík, M.; Valkovič, P.; Hančinová, V.; Krížová, L.; Tóthová, L.; Celec, P. Clin. Biochem. $2015,48,24-28$.

(17) Geldenhuys, W. J.; Darvesh, A. S. Expert Rev. Neurother. 2015, 15, 3-5.

(18) Colamartino, M.; Santoro, M.; Duranti, G.; Sabatini, S.; Ceci, R.; Testa, A.; Padua, L.; Cozzi, R. Neurotoxic. Res. 2015, 27, 106-117.

(19) Jaffer, O. A.; Carter, A. B.; Sanders, P. N.; Dibbern, M. E.; Winters, C. J.; Murthy, S.; Ryan, A. J.; Rokita, A. G.; Prasad, A. M.; Zabner, J.; Kline, J. N.; Grumbach, I. M.; Anderson, M. E. Am. J. Respir. Cell Mol. Biol. 2015, 52, 106-115.

(20) Tataranno, M. L.; Perrone, S.; Longini, M.; Buonocore, G. Oxid. Med. Cell. Longevity 2015, 2015, No. 108251, DOI: 10.1155/2015/108251.

(21) Whittaker, J. W. Arch. Biochem. Biophys. 2012, 525, 111-120.

(22) Signorella, S.; Hureau, C. Coord. Chem. Rev. 2012, 256, 1229-1245.

(23) Kubota, R.; Asayama, S.; Kawakami, H. Chem. Commun. 2014, 50, 15909-15912.

(24) Ledesma, G. N.; Eury, H.; Anxolabéhère-Mallart, E.; Hureau, C.; Signorella, S. R. J. Inorg. Biochem. 2015, 146, 69-76.

(25) Kar, P.; Drew, M. G. B.; Ghosh, A. Inorg. Chim. Acta 2013, 405, 349-355. 
(26) Kubota, R.; Imamura, S.; Shimizu, T.; Asayama, S.; Kawakami, H. ACS Med. Chem. Lett. 2014, 5, 639-643.

(27) Noritake, Y.; Umezawa, N.; Kato, N.; Higuchi, T. Inorg. Chem. 2013, 52, 3653-3662.

(28) Palopoli, C.; Duhayon, C.; Tuchagues, J.-P.; Signorella, S. Dalton Trans 2014, 43, $17145-17155$.

(29) Reinert, P.; Garcia, B.; Morin, C.; Badiei, A.; Perriat, P.; Tillement, O.; Bonneviot, L. Stud. Surf. Sci. Catal. 2003, 146, 133-136.

(30) Beck, J. S.; Vartuli, J. C.; Roth, W. J.; Leonowicz, M. E.; Kresge, C. T.; Schmitt, K. D.; Chu, C. T. W.; Olson, D. H.; Sheppard, E. W. J. Am. Chem. Soc. 1992, 114, 10834-10843.

(31) Zhang, K.; Chen, H.-L.; Albela, B.; Jiang, J.-G.; Wang, Y.-M.; He, M.-Y.; Bonneviot, L. Eur. J. Inorg. Chem. 2011, 2011, 59-67.

(32) Chaignon, J.; Stiriba, S.-E.; Lloret, F.; Yuste, C.; Pilet, G.; Bonneviot, L.; Albela, B.; Castro, I. Dalton Trans. 2014, 43, 9704-9713.

(33) Du, L.; Li, J.; Chen, C.; Liu, Y. Free Radical Res. 2014, 48, 1061-1069.

(34) Vivero-Escoto, J. L.; Slowing, I. I.; Trewyn, B. G.; Lin, V. S.-Y. Small 2010, 6, 1952-1967.

(35) Fernández, G.; Corbella, M.; Aullón, G.; Maestro, M. A.; Mahía, J. Eur. J. Inorg. Chem. 2007, 2007, 1285-1296.

(36) Gómez, V.; Corbella, M.; Roubeau, O.; Teat, S. J. Dalton Trans. 2011, 40, 11968.

(37) Gómez, V.; Corbella, M.; Aullón, G. Inorg. Chem. 2010, 49, 1471-1480.

(38) Sala, T.; Sargent, M. V. J. Chem. Soc., Chem. Commun. 1978, 6, 253-254.

(39) Bonneviot, L.; Morin, M.; Badiel, A. Patent WO 01/55031 A1, 2001.

(40) Zhang, K.; Albela, B.; He, M.-Y.; Wang, Y.; Bonneviot, L. Phys. Chem. Chem. Phys. 2009, 11, 2912.

(41) Chaignon, J.; Bouizi, Y.; Davin, L.; Calin, N.; Albela, B.; Bonneviot, L. Green Chem. 2015, 17, 3130-3140.

(42) SADABS, Version 2008/1; Sheldrick, Bruker AXS Inc., 2008.

(43) Sheldrick, G. M. Acta Crystallogr., Sect. A: Found. Crystallogr. 2008, 64, 112-122.

(44) Gagliardi, L. G.; Castells, C. B.; Ràfols, C.; Rosés, M.; Bosch, E. Anal. Chem. 2007, 79, 3180-3187.

(45) Kahn, O. Molecular Magnetism; VCH, 1993.

(46) Chilton, N. F.; Anderson, R. P.; Turner, L. D.; Soncini, A.; Murray, K. S. J. Comput. Chem. 2013, 34, 1164-1175.

(47) Aromí, G.; Telser, J.; Ozarowski, A.; Brunel, L.-C.; Stoeckli-Evans, H.-M.; Krzystek, J. Inorg. Chem. 2005, 44, 187-196.

(48) Duboc, C.; Ganyushin, D.; Sivalingam, K.; Collomb, M.-N.; Neese, F. J. Phys. Chem. A 2010, 114, 10750-10758.

(49) Boča, R. Coord. Chem. Rev. 2004, 248, 757-815. 
800

801

802

803

804

805

806

807

808

809

810

811

812

813

814

815

816

817

818

819

820

821

822

823

824

825

826

827

828

829

(50) G omez-Coca, S.; Cremades, E.; Aliaga-Alcalde, N.; Ruiz, E. J. Am. Chem. Soc. 2013, 135, 7010-7018.

(51) Sing, K. S. W. Pure Appl. Chem. 1985, 57, 603-619.

(52) Abry, S.; Lux, F.; Albela, B.; Artigas-Miquel, A.; Nicolas, S.; Jarry, B.; Perriat, P.; Lemercier, G.; Bonneviot, L. Chem. Mater. 2009, 21, 2349-2359.

(53) Calmettes, S.; Albela, B.; Hamelin, O.; Ménage, S.; Miomandre, F.; Bonneviot, L. New J. Chem. 2008, 32, 727.

(54) Broekhoff, J. C. P.; De Boer, J. H. J. Catal. 1967, 9, 15-27.

(55) Deacon, G. B.; Phillips, R. J. Coord. Chem. Rev. 1980, 33, 227-250.

(56) Abry, S.; Thibon, A.; Albela, B.; Delichère, P.; Banse, F.; Bonneviot, L. New J. Chem. 2009, 33,484 .

(57) Zhang, K.; Lam, K.-F.; Albela, B.; Xue, T.; Khrouz, L.; Hou, Q.-W.; Yuan, E.-H.; He, M.-Y.; Bonneviot, L. Chem. - Eur. J. 2011, 17, 14258-14266.

(58) Manceau, A.; Marcus, M. A.; Grangeon, S. Am. Mineral. 2012, 97, 816-827.

(59) Bossek, U.; Hummel, H.; Weyhermüller, T.; Wieghardt, K.; Russell, S.; van der Wolf, L.; Kolb, U. Angew. Chem., Int. Ed. Engl. 1996, 35, 1552-1554.

(60) Chalmin, E.; Farges, F.; Brown, G. E., Jr Contrib. Mineral. Petrol. 2009, 157, 111-126.

(61) Moulder, J. F. Handbook of X-ray Photoelectron Spectroscopy: A Reference Book of Standard Spectra for Identification and Interpretation of XPS Data; Physical Electronics Division, PerkinElmer Corporation, 1992.

(62) Bratt, A.; Barron, A. R. XPS of Carbon Nanomaterials; Openstax CNX, 2011.

(63) Cerrato, J. M.; Hochella, M. F.; Knocke, W. R.; Dietrich, A. M.; Cromer, T. F. Environ. Sci. Technol. 2010, 44, 5881-5886.

(64) Nelson, A. J.; Reynolds, J. G.; Christou, G. J. Appl. Phys. 2003, 93, 2536-2539.

(65) García-Martín, J.; López-Garzón, R.; Godino-Salido, M. L.; Cuesta-Martos, R.; GutiérrezValero, M. D.; Arranz-Mascarós, P.; Stoeckli-Evans, H. Eur. J. Inorg. Chem. 2005, 2005, 3093-3103.

(66) Corbella, M.; Fernández, G.; González, P.; Maestro, M.; Font-Bardia, M.; Stoeckli-Evans, H. Eur. J. Inorg. Chem. 2012, 2012, 2203-2212.

(67) Gómez, V.; Corbella, M. Eur. J. Inorg. Chem. 2012, 2012, 3147-3155.

(68) Geary, W. J. Coord. Chem. Rev. 1971, 7, 81-122.

(69) Fernández, G.; Corbella, M.; Alfonso, M.; Stoeckli-Evans, H.; Castro, I. Inorg. Chem. 2004, 43, 6684-6698.

(70) Palopoli, C.; Bruzzo, N.; Hureau, C.; Ladeira, S.; Murgida, D.; Signorella, S. Inorg. Chem. 2011, 50, 8973-8983.

(71) Iler, R. K. The Chemistry of Silica: Solubility, Polymerization, Colloid and Surface Properties and Biochemistry of Silica; Wiley-Interscience: New York, 1979. 
(72) Calmettes, S. Conception d'un catalyseur par greffage d'un complexe de rutheń ium en milieu confiné ; Application à l'oxydation seĺ ective. Ph.D. Thesis, Ecole Normale Supeŕ ieure de Lyon-ENS LYON; Université Claude Bernard-Lyon I: France, 2008.

833 (73) Whittaker, M. M.; Barynin, V. V.; Igarashi, T.; Whittaker, J. W. Eur. J. Biochem. 2003, 270, 834 1102-1116. Inorganic Chemistry Article DOI

835 
838 Figure 1 Crystal structure of the cationic complex of compound 1. Hydrogen atoms were omitted for 839 clarity.

840

Figure 2. Crystal structure of the cationic complex of compound 2.Hydrogen atoms were omitted for clarity.

843

Figure 3 Figure 3. $\chi \mathrm{MT}$ vs $\mathrm{T}$ plots for compounds 1 (blue) and 2 (green); and $\mathrm{M} / \mathrm{N} \mu \beta$ vs HT plot (inset) for compound 2 at six different values of the magnetic field. The solid lines are the best fits of the experimental data.

847

848

Fig. 4 Figure 4. Synthetic procedure to obtain the $\mathrm{Mn}-\mathrm{SiO} 2-$ based material [Mn2O]@SiO2 from "asmade" silica ( $\mathrm{SiO} 2-\mathrm{CTA})$. The insertion performed from compound 1 or 2 leads to the same material. Abbreviations: CTA+, cetyltrimethylammonium; TMA+, tetramethylammonium.

Figure 5. N2 adsorption (•) and desorption (०) isotherms at $77 \mathrm{~K}$ of materials $\mathrm{SiO} 2-\mathrm{Ex}$ (blue),

SiO2-TMA (green), and [Mn2O]@SiO2 (red).

854

855

Figure 6. Infrared spectra (range 1800-1100 cm-1) of compound 1 (blue), compound 2 (green) and

856 material [Mn2O]@SiO2 (red). The star $(*)$, the arrows $(\downarrow)$, and circles $(\bullet)$ indicate IR vibrations of TMA+, carboxylate, and bipyridine, respectively.

858

859

Figure 7. XPS spectra of Mn 3s (a, b) and N 1s (c, d) peaks for compound $1(a, c)$ and material [Mn2O]@SiO2 (b, d). The solid black lines correspond to the experimental plots; the dotted lines correspond to the background, and the colored lines to the deconvoluted curves.

Figure 8. $\chi \mathrm{MT}$ vs T plots for compounds 1 (blue), 2 (green), and material [Mn2O]@SiO2 (red). The 865

Figure 9. Catalase activity of a $0.8 \mathrm{mM}$ solutions of compounds 1 (blue) and 2 (green) in acetonitrile-water 9:1 (v/v), with [H2O2]0 $=1.05 \mathrm{M}$.

Figure 10. Catalase activity of $0.8 \mathrm{mM}$ solutions of compound 2 in acetonitrile-water 9:1 (v/v) at different $\mathrm{pH}$ values, with $[\mathrm{H} 2 \mathrm{O} 2] 0=1.05 \mathrm{M}$. 
872 Figure 11. Catalase activity of material [Mn2O]@SiO2 (0.8 mM based on [MnIII2]) (red) and for

873 compound 2 at $\mathrm{pH}=7.3$ (green) and 9.8 (orange) in acetonitrile-water 9:1 (v/v), with [H2O2]0 $=1.05$

$874 \mathrm{M}$.

875

876 Figure 12. Turnover number vs time for three successive additions (at $\mathrm{t}=0,500$, and $1230 \mathrm{~s}$ ) of $\mathrm{H} 2 \mathrm{O} 2$

877 (1312 equiv) to a suspension of material [Mn2O]@SiO2 (0.8 mM based on [MnIII2]) in $\mathrm{CH} 3 \mathrm{CN}-\mathrm{H} 2 \mathrm{O}$

$8789: 1(\mathrm{v} / \mathrm{v})$. Red lines correspond to the initial rate of $\mathrm{H} 2 \mathrm{O} 2$ dismutation, and the green lines correspond to 879 the saturation TON after each addition.

880

881 Figure 13. Turnover number vs time for 1 (blue), 2 (green), and [Mn2O]@SiO2 (0.8 mM based on 882 [MnIII2]) (red) in water, with $[\mathrm{H} 2 \mathrm{O} 2] 0=1.05 \mathrm{M}$.

883 


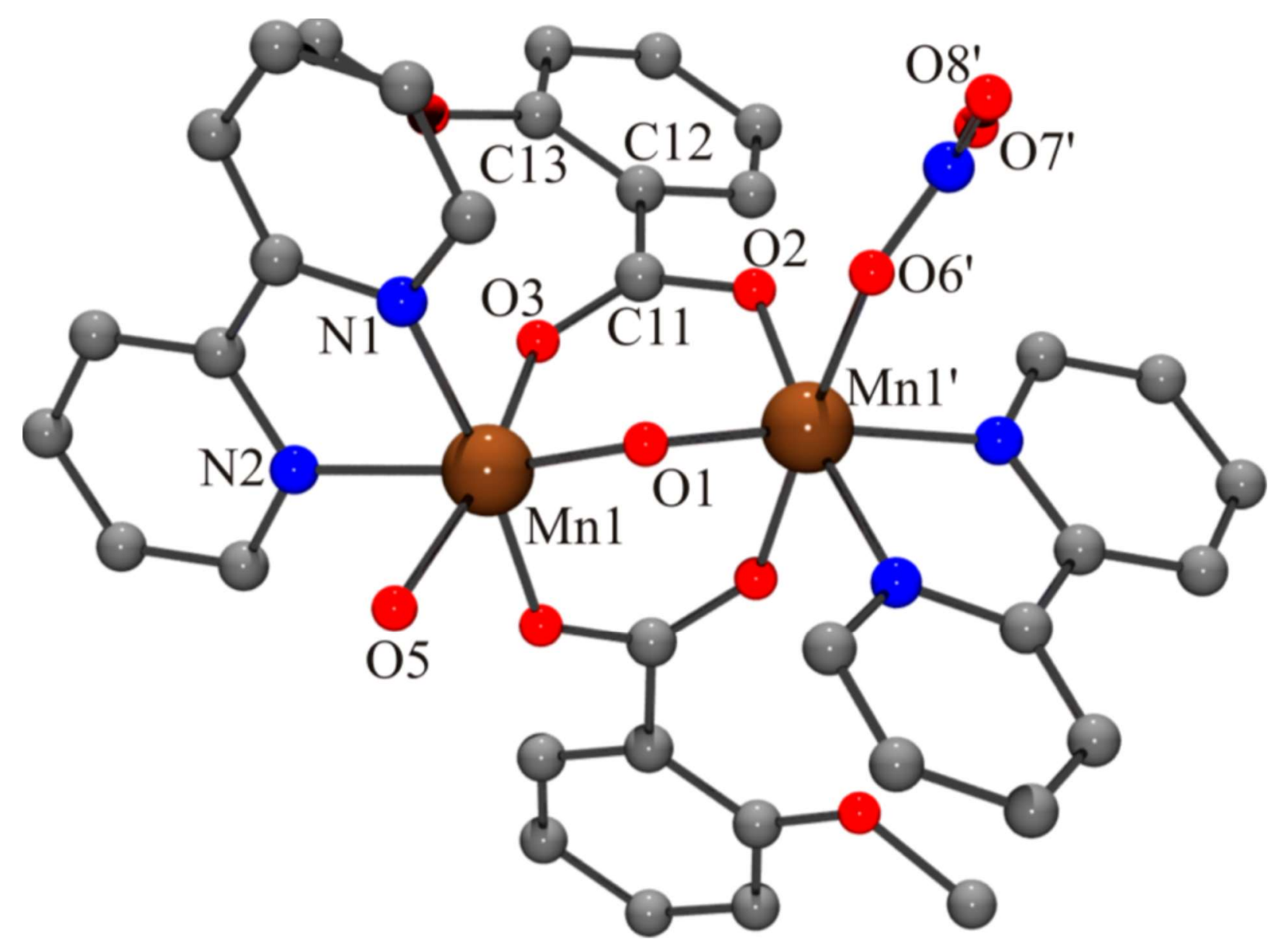




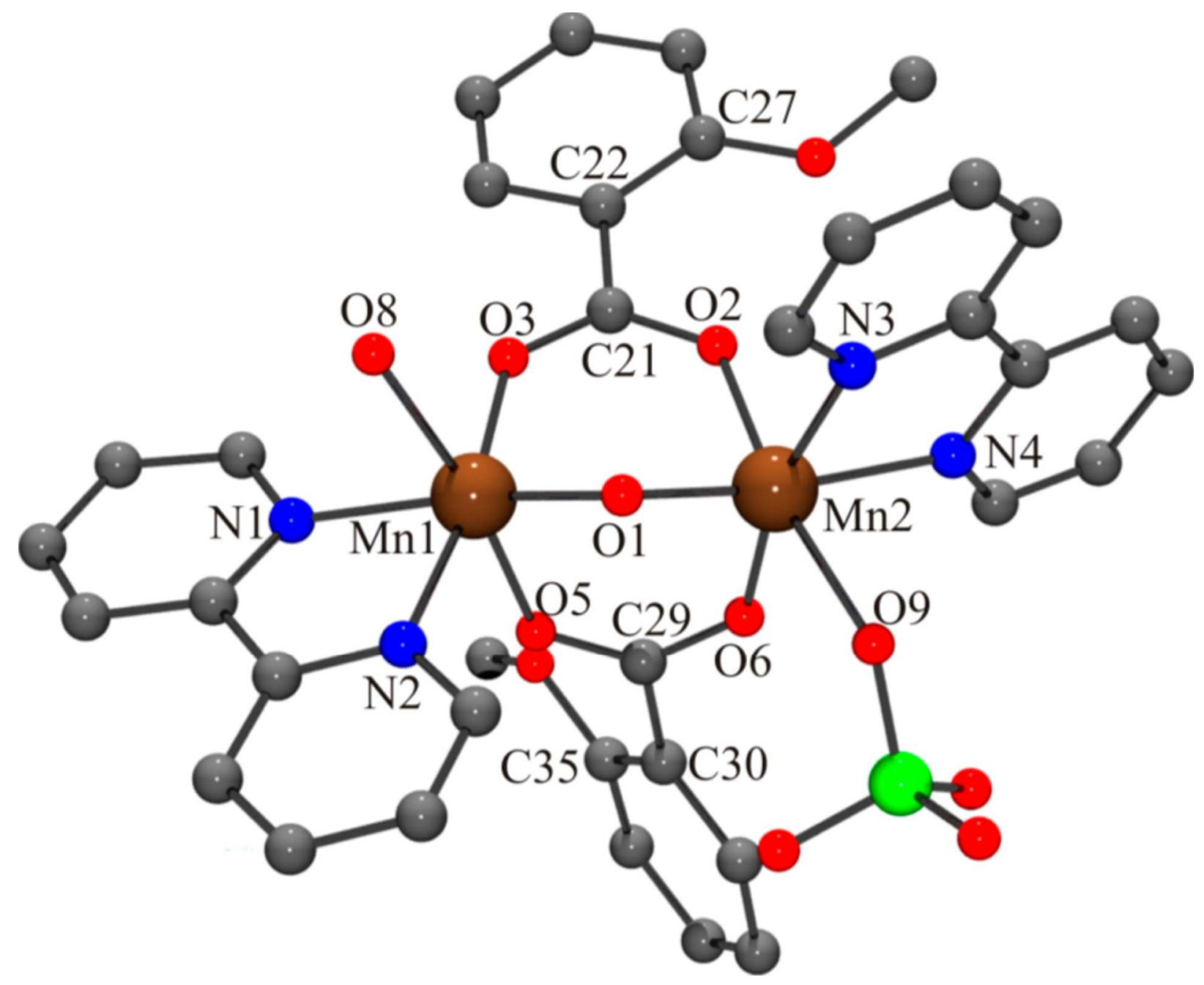


FIGURE 3

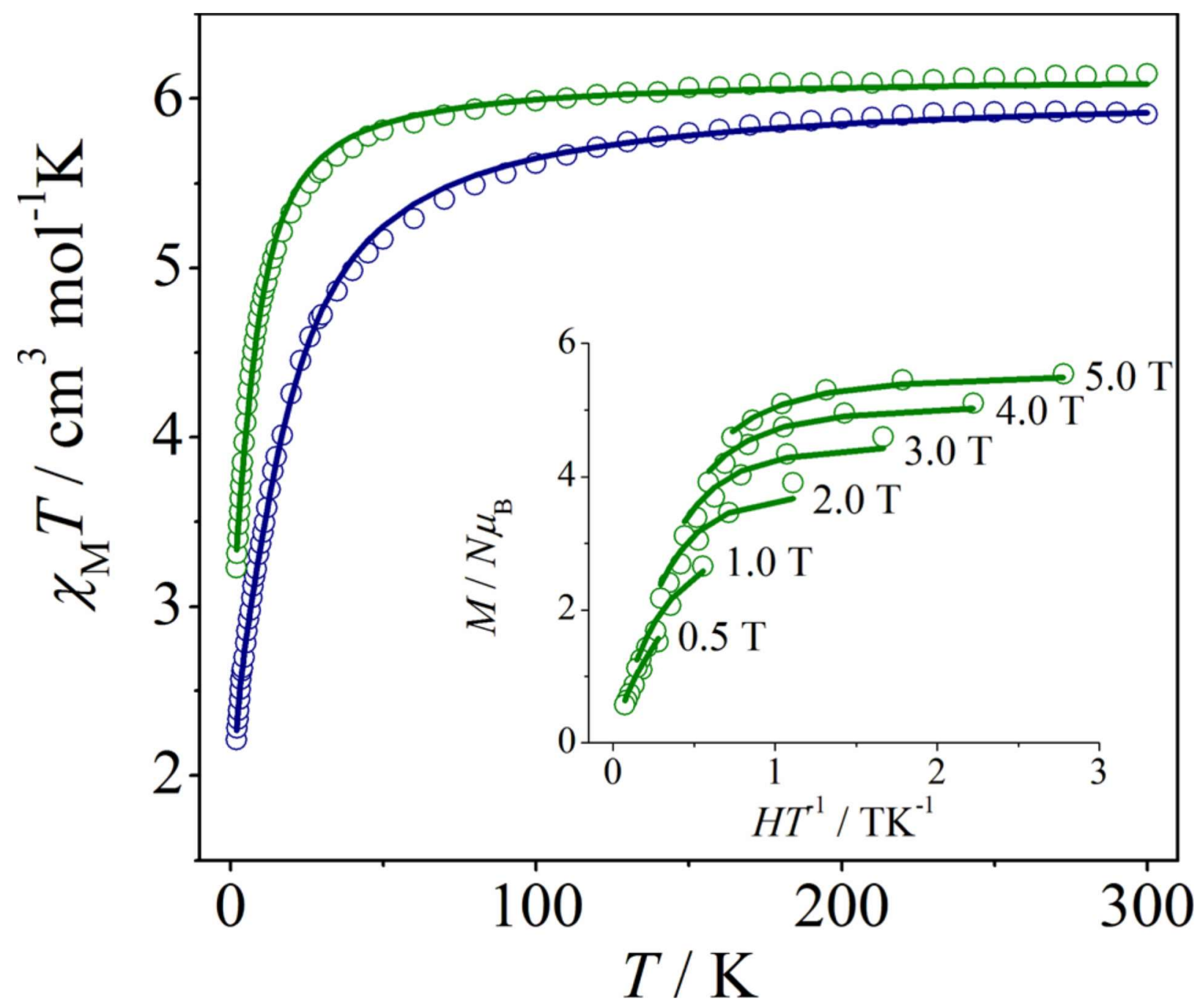


FIGURE 4

909
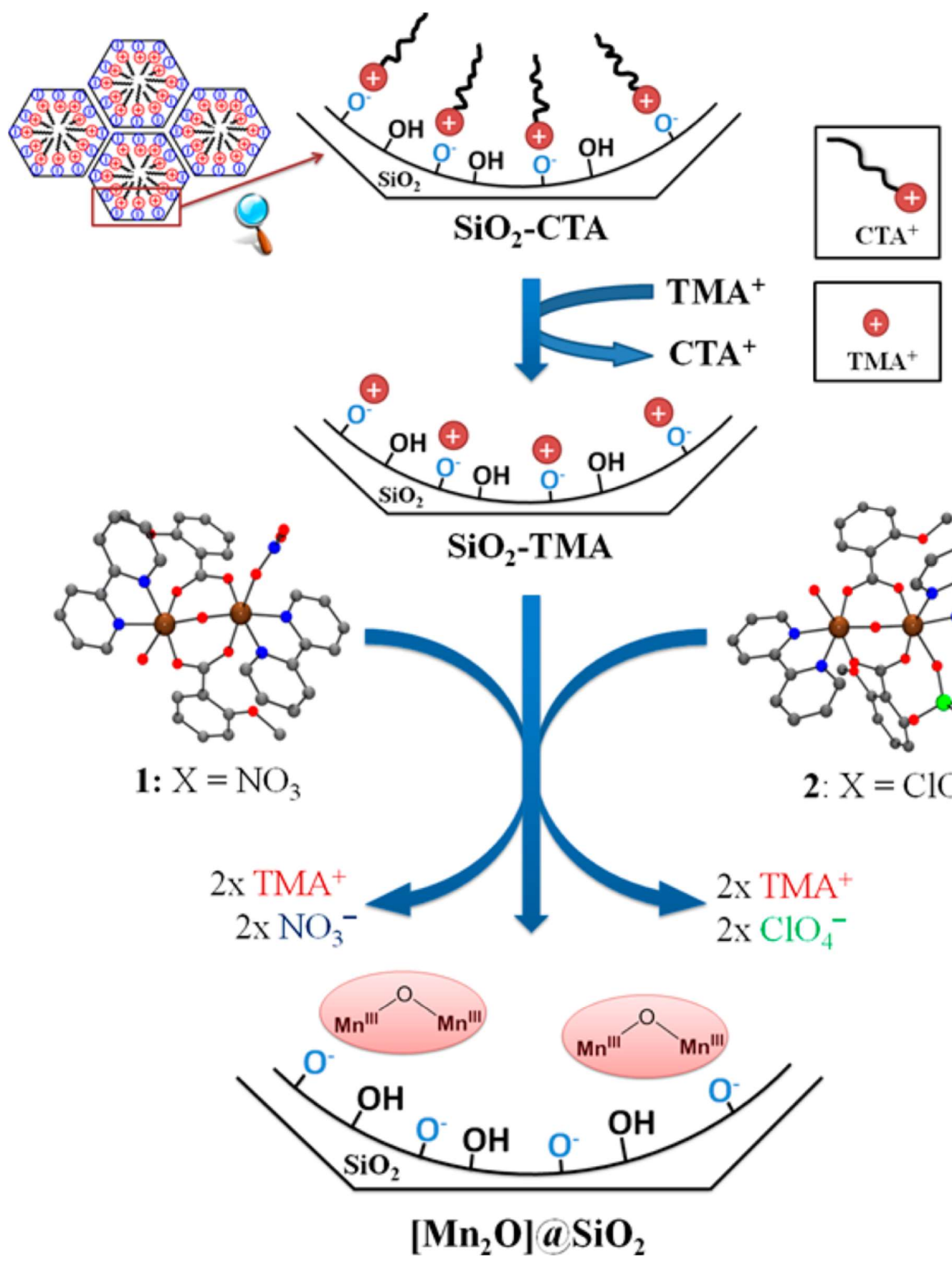
FIGURE 5

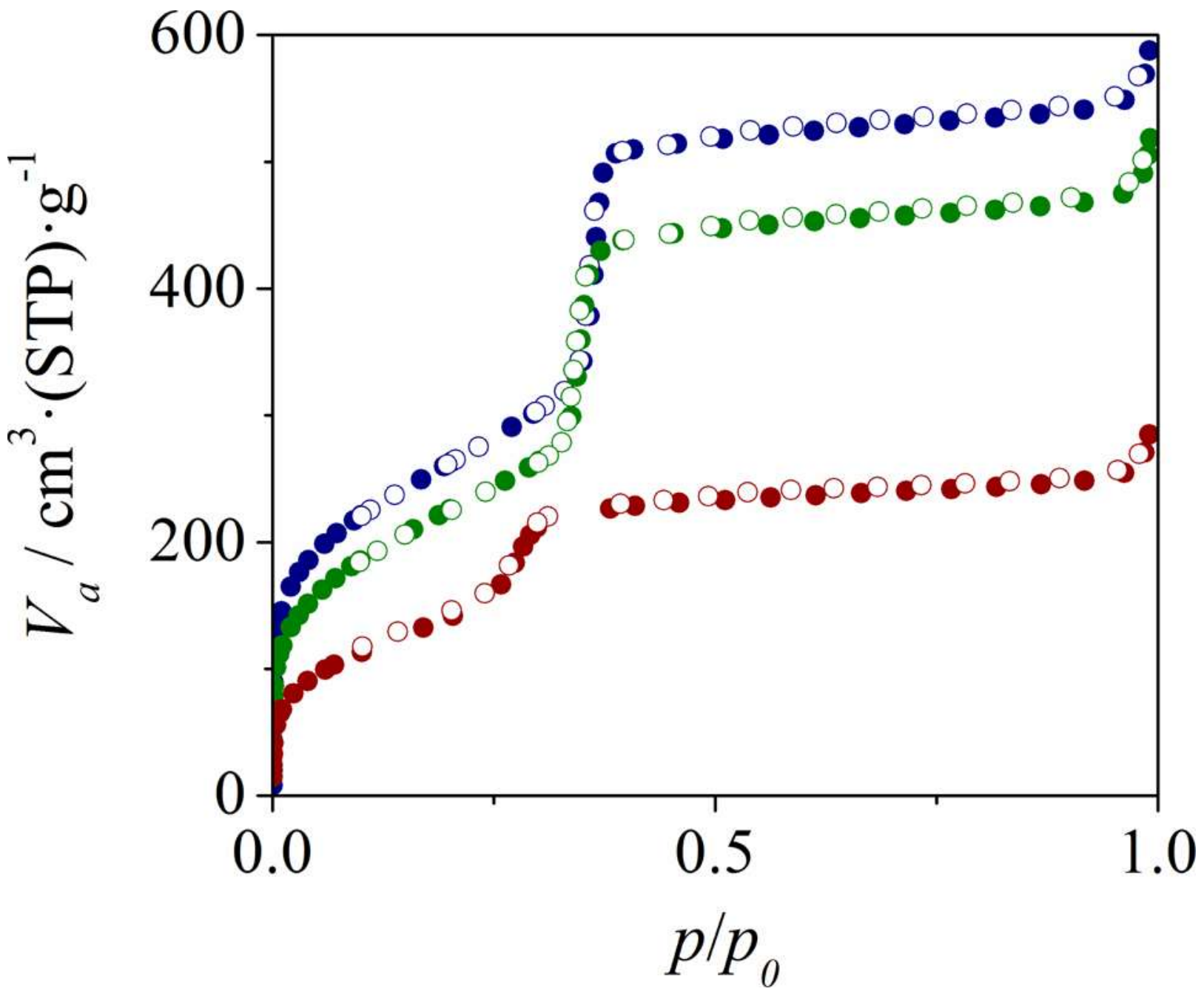


FIGURE 6

923

924

925

1800

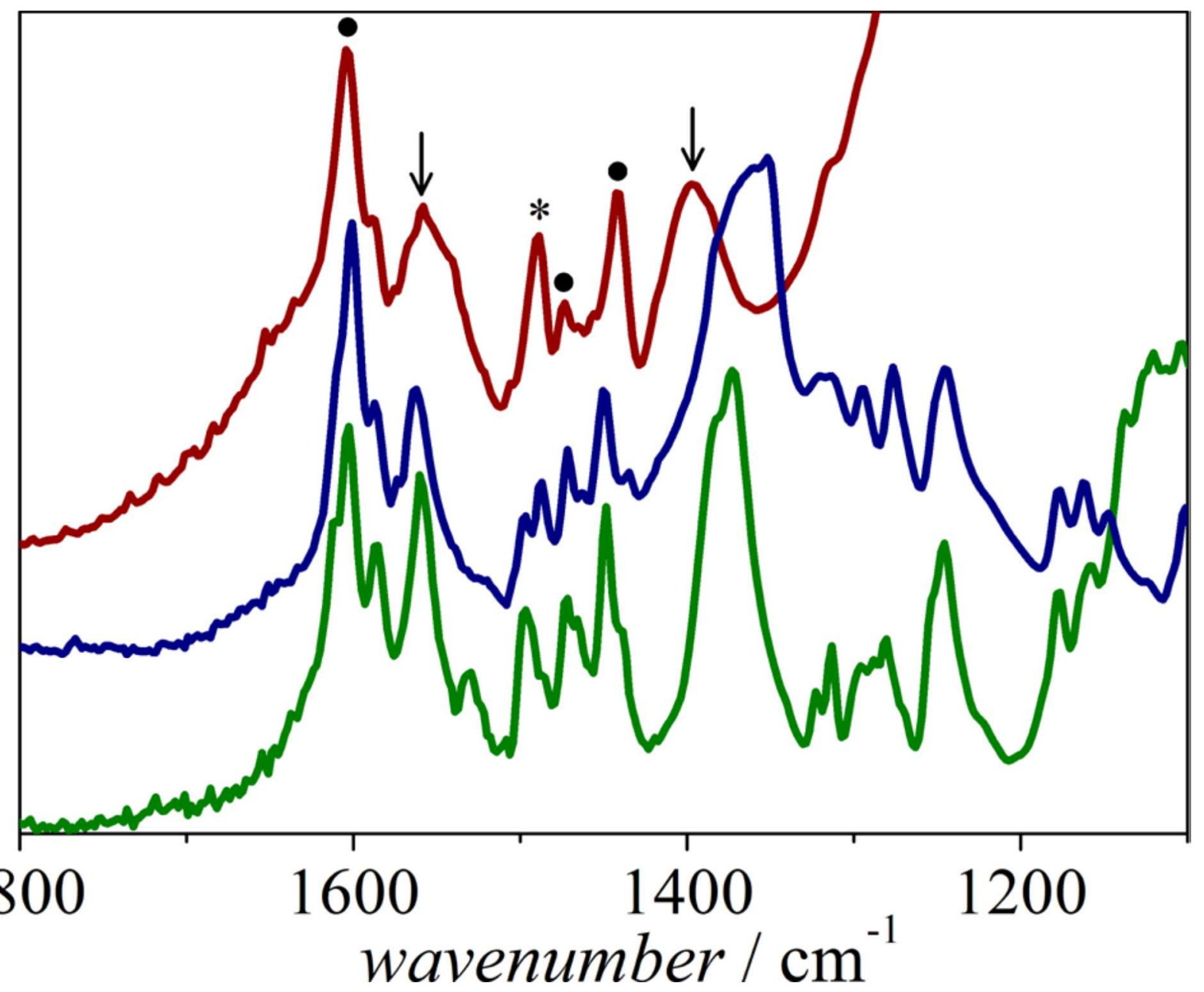

927

928 

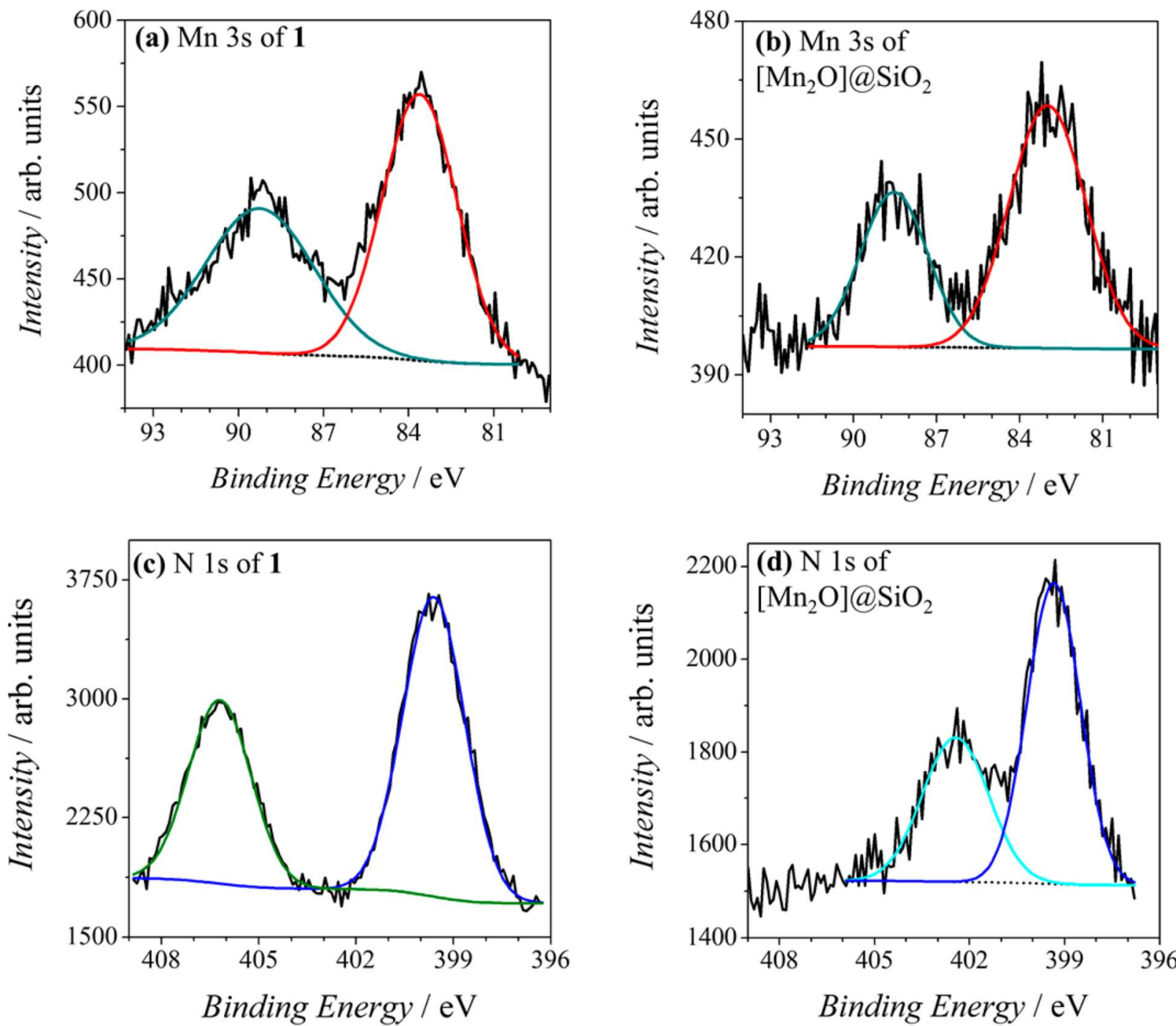


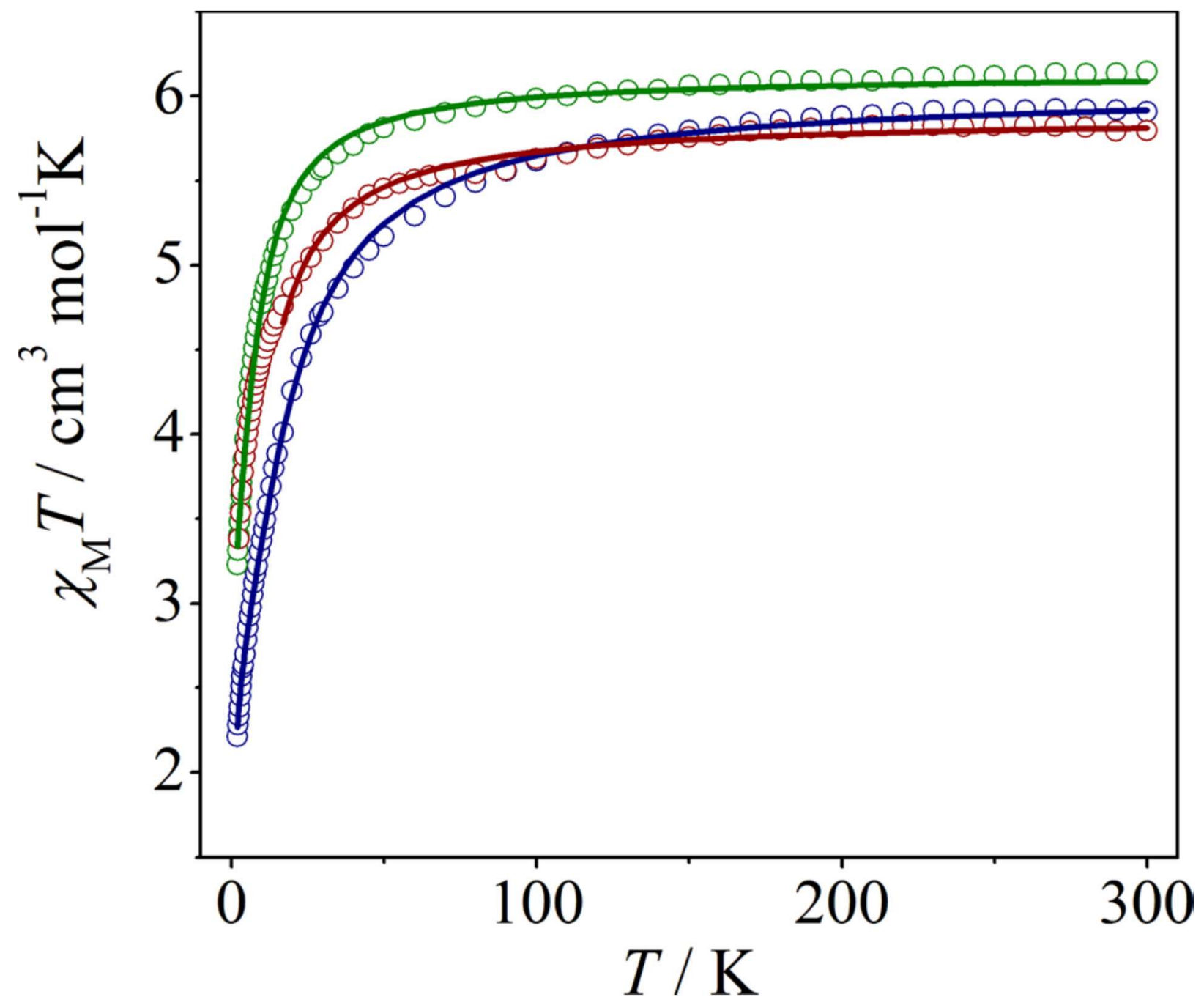




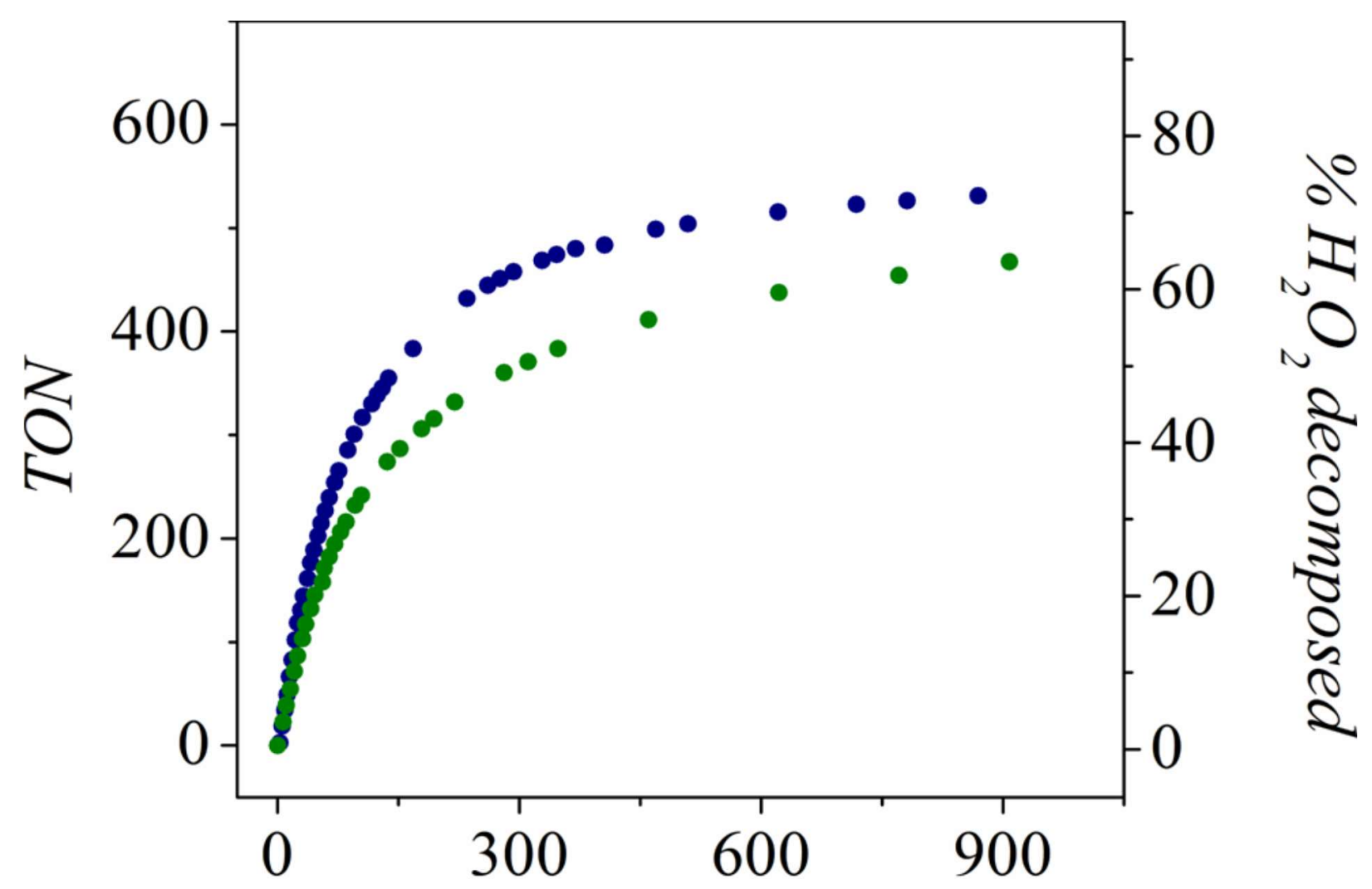




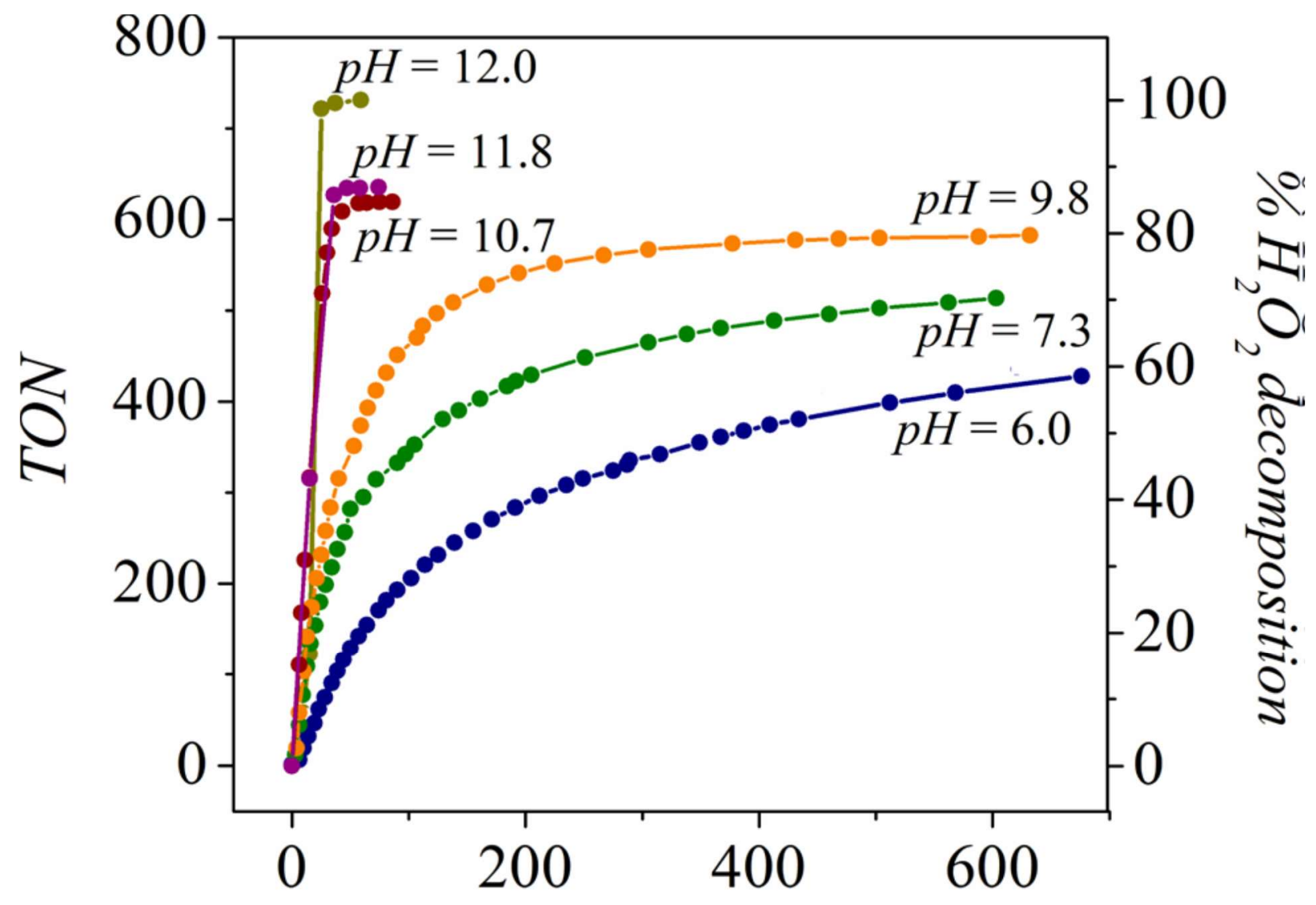


FIGURE 11

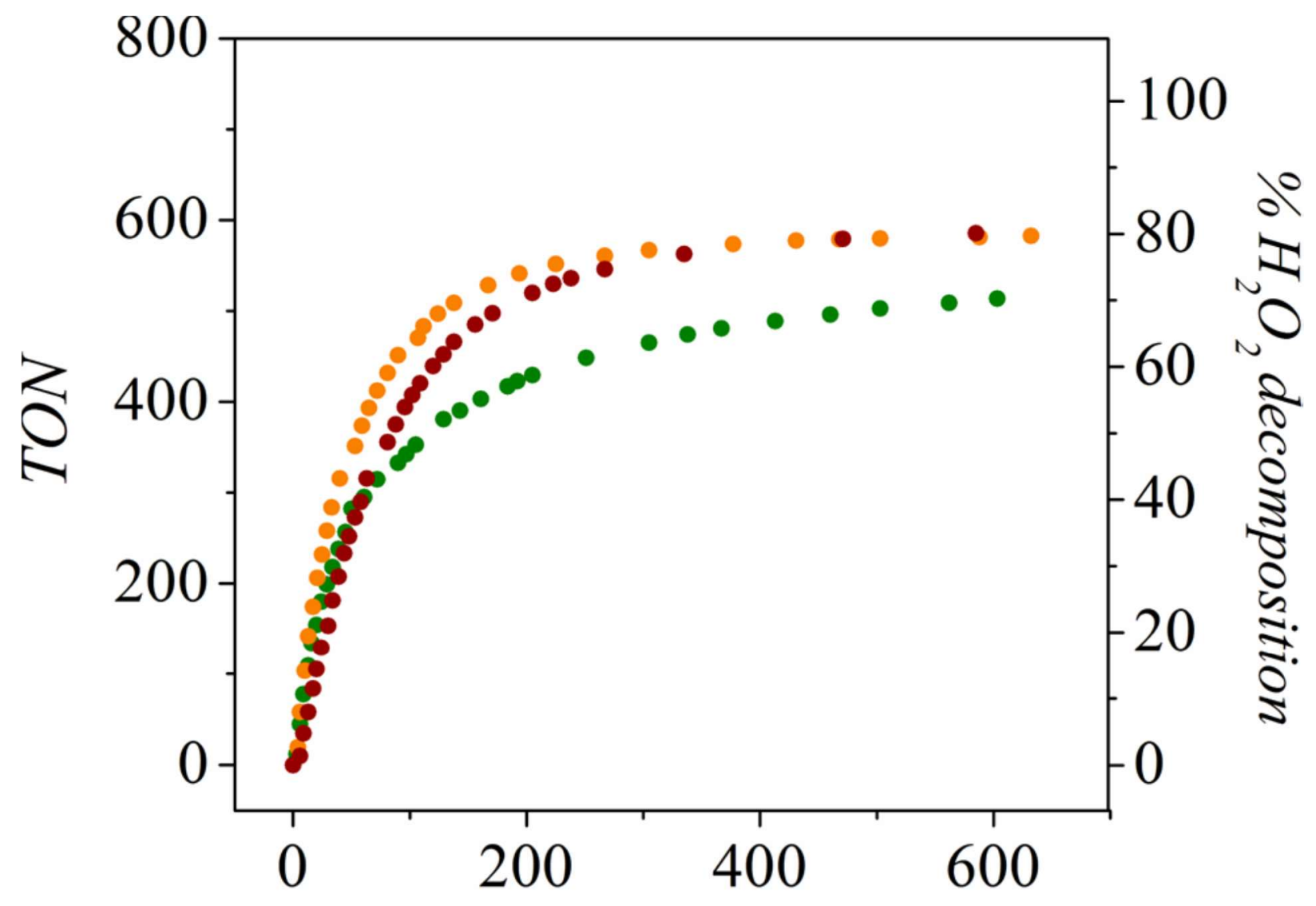




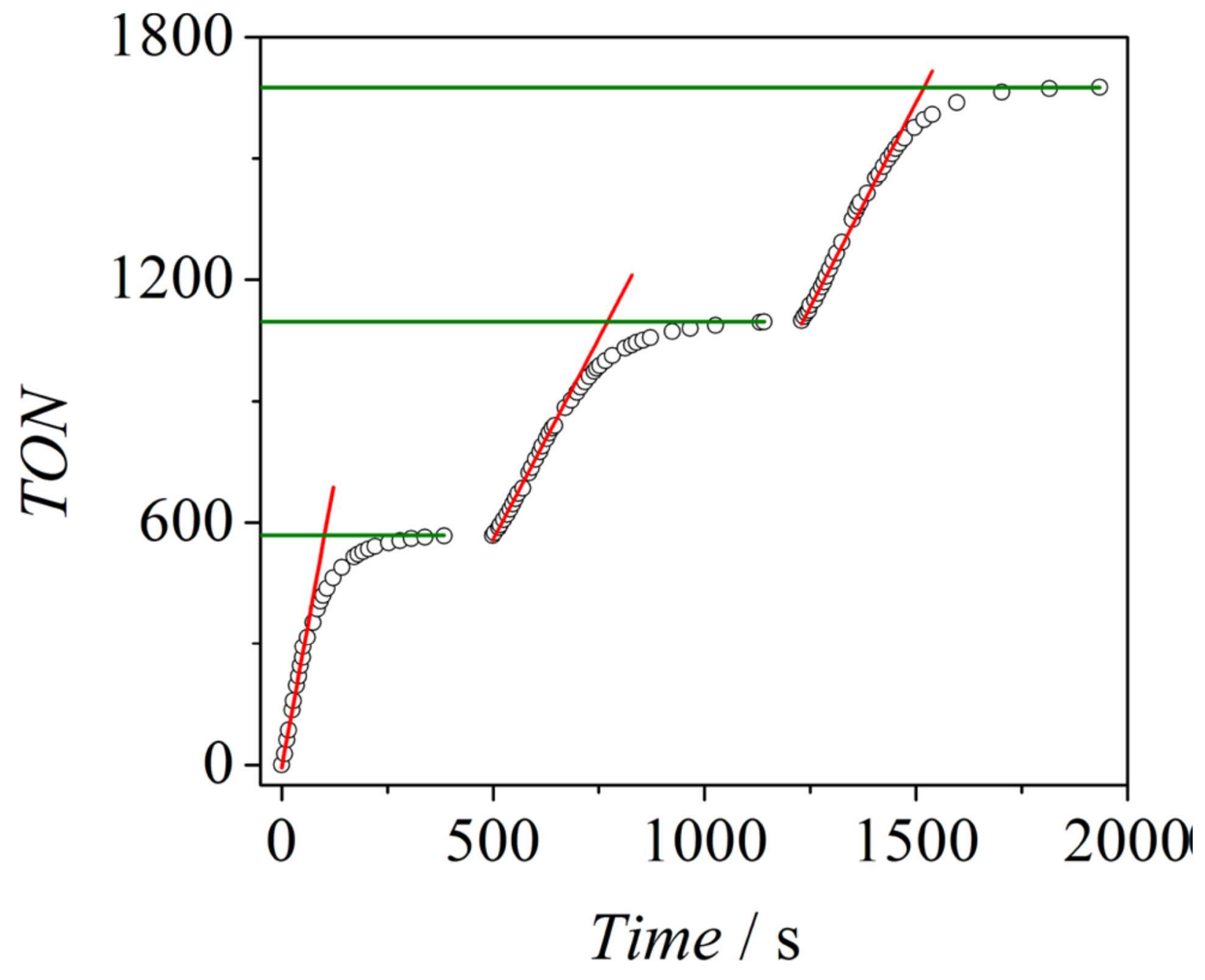




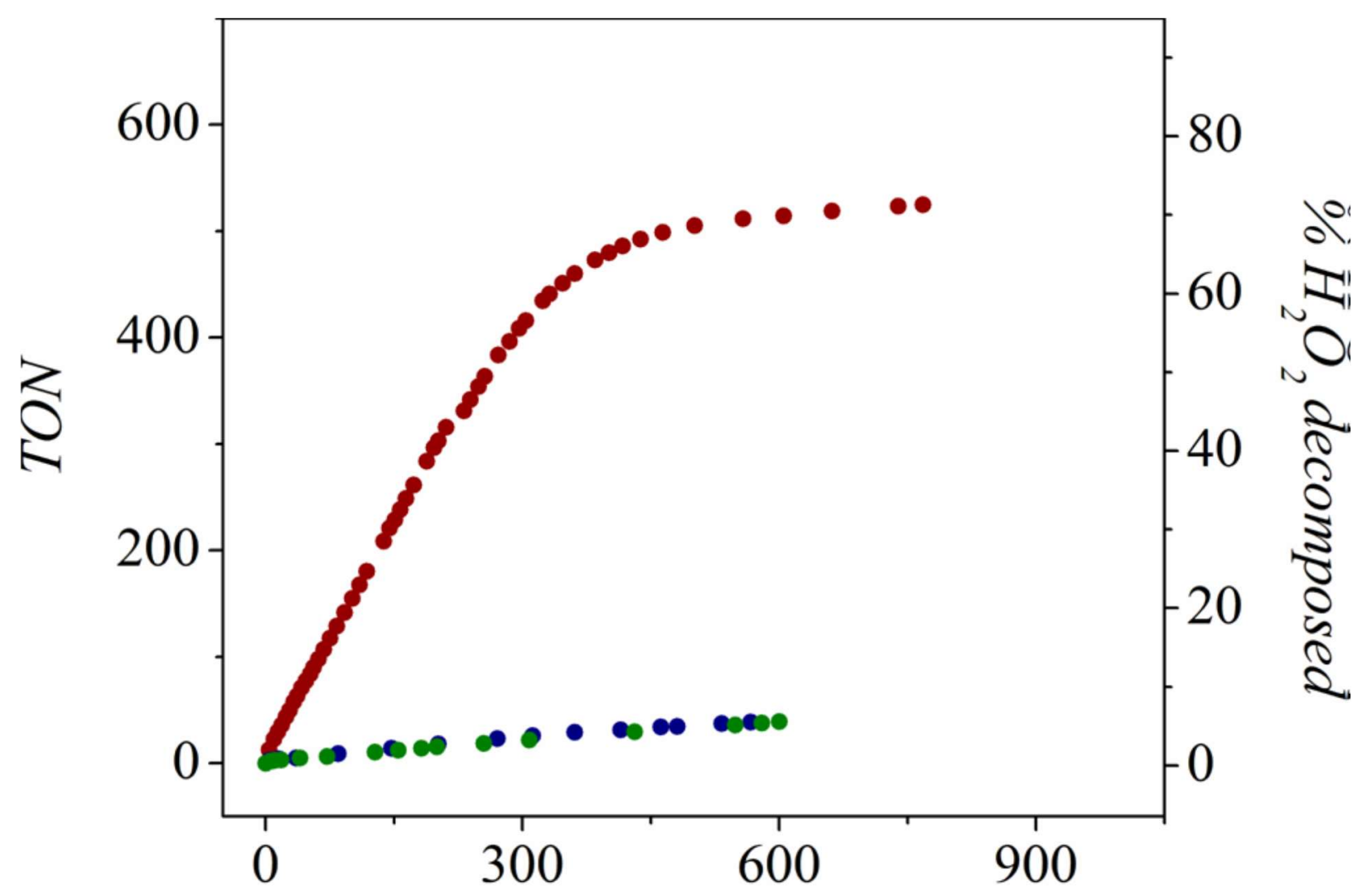


972 Table 1. Crystal Data and Structure Refinement for Compounds 1 and 2)

\begin{tabular}{|c|c|c|}
\hline & $1 \mathrm{H}_{1} \mathrm{O} 0.5 \mathrm{CH}_{3} \mathrm{CV}$ & $2 \mathrm{CH}, \mathrm{CN}$ \\
\hline farmal & $\mathrm{C}_{w} \mathrm{H}_{u 2} \mathrm{M}_{2} \mathrm{~N}_{12} \mathrm{O}_{4}{ }^{*}$ & $\mathrm{C}_{\mathbf{s}} \mathrm{H}_{3}, \mathrm{C}_{2} \mathrm{M}=\mathrm{m}_{2} \mathrm{~N}_{2} \mathrm{O}_{14}$ \\
\hline$F_{w}(g /=0)$ & $36 \pi 028$ & 99849 \\
\hline crost cobe, lablat & grees, noode & grees, soodle \\
\hline $\mathbf{T}(\mathbf{K})$ & $100(2)$ & $100(2)$ \\
\hline$\lambda(\mathrm{Mb} \mathrm{Ka}), \lambda$ & 0.7073 & a.7073 \\
\hline copsal sine (u) & $0.65 \times 0.26 \times 0.21$ & $0.57 \times 0.07 \times 0.00$ \\
\hline crobal yze= & mobodinic & mobodrie \\
\hline space grow & $\mathrm{C}_{2} / \mathrm{c}$ & $\mathrm{P} 21 / \mathrm{c}$ \\
\hline$a, \lambda$ & $16.3701(6)$ & $17826(7)$ \\
\hline$b, \lambda$ & $24.5812(9)$ & $21265(7)$ \\
\hline$<, \lambda$ & $9.960(4)$ & $10.759(4)$ \\
\hline f, dag & $99.328(1)$ & $95.72(1)$ \\
\hline$V, \Lambda^{n}$ & $39549(3)$ & $40.58(2)$ \\
\hline$z$ & 1 & 4 \\
\hline 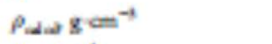 & 1.541 & 1.631 \\
\hline$\mu,==^{-1}$ & 0.78 & 0.835 \\
\hline $\mathrm{F}(\boldsymbol{\infty})$ & 1878 & 2032 \\
\hline$\theta$ suge, dag & 2.99 to 2.508 & 1.15 to 2081 \\
\hline ca platames to & $998 \%$ & $99.5 \%$ \\
\hline \multirow[t]{3}{*}{ isdex ango } & $h--19 \rightarrow 19$ & $h--17 \rightarrow 17$ \\
\hline & $k=-29 \rightarrow 29$ & $k=0 \rightarrow 21$ \\
\hline & $1--11 \rightarrow 11$ & $1-0 \rightarrow 10$ \\
\hline data/retainb/purale bers & $3515 / 106 / 306$ & $4226 / 1 / 562$ \\
\hline GOF od F & 1.110 & 0.824 \\
\hline$R_{1}^{2}, a R_{2}^{*}[I>2 s(I)]$ & $0.0500,0.1515$ & $0.0852,0.0768$ \\
\hline$R_{1}{ }^{2}, a R_{2}^{*}(x)$ data) & $0.0520,0.1525$ & 0.091400966 \\
\hline
\end{tabular}

975 
979 Table 2 Selected Interatomic Distances $(\AA)$ and Angles (deg) for Compound 1a 980

\begin{tabular}{|c|c|}
\hline $\mathrm{M}=\mathrm{l}-\mathrm{O} 1$ & $1.720(1)$ \\
\hline $\mathrm{M}=\mathrm{l}-\mathrm{O} 2$ & $19 \pi(2)$ \\
\hline $\mathrm{M}=\mathrm{l}-\mathrm{O} 3$ & $2.160(2)$ \\
\hline $\mathrm{M}=1-05 / \mathrm{M}=\mathrm{l}^{\prime}-\infty 6^{\prime}$ & $2200(3)$ \\
\hline $\mathrm{M}=\mathrm{N}-\mathrm{N} \mid$ & $206 \nabla(3)$ \\
\hline $\mathrm{M}=1-\mathrm{N} 2$ & $2064(3)$ \\
\hline $\mathrm{M}=\mathrm{l}-\mathrm{M}=\mathrm{l}^{\prime}$ & $3.1412(9)$ \\
\hline $\mathrm{M}=1-\mathrm{O} 1-\mathrm{M}=\mathrm{I}^{\prime}$ & $123.5(2)$ \\
\hline $\mathrm{O} 1-\mathrm{M}=1-\mathrm{N}_{2}$ & $16848(9)$ \\
\hline $\mathrm{O}-\mathrm{M}=\mathrm{l}-\mathrm{N} 1$ & $170.3(1)$ \\
\hline O3-M: -05 & $1747(1)$ \\
\hline O5-Mal-Mal'-O6 & $\pi .1(1)$ \\
\hline $\mathrm{O} 3-\mathrm{Cl}-\mathrm{Cl}-\mathrm{Cl} 3$ & $362(5)$ \\
\hline
\end{tabular}


984 Table 3. Selected Interatomic Distances $(\AA)$ and Angles (deg) for Compound 2a

985

986

\begin{tabular}{|c|c|}
\hline $\mathrm{M}=\mathrm{l}=\mathrm{O}$ & $1.784(4)$ \\
\hline $\mathrm{M}=\mathrm{l}-\mathrm{O}_{3}$ & $1965(4)$ \\
\hline $\mathrm{M}=1-\mathrm{N} 2$ & $2056(5)$ \\
\hline $\mathrm{M}=\mathrm{l}-\mathrm{N} 1$ & $2060(5)$ \\
\hline $\mathrm{M}=\mathrm{l}=\mathrm{O} 5$ & $2.177(4)$ \\
\hline $\mathrm{M}=\mathrm{l}=\mathrm{OS}$ & $2.219(4)$ \\
\hline $\mathrm{O} 3-\mathrm{M}=1-\mathrm{N} 2$ & $1706(2)$ \\
\hline $\mathrm{O} 1-\mathrm{M}=1-\mathrm{M} 1$ & $1667(2)$ \\
\hline O5-Mal-08 & $1708(2)$ \\
\hline $\mathrm{M}=1-\mathrm{M}=2$ & $3.139(2)$ \\
\hline $\mathrm{M}=1-01-\mathrm{M}=2$ & $1228(2)$ \\
\hline $08-\mathrm{M}=1-\mathrm{M}=2-\infty$ & $952(2)$ \\
\hline
\end{tabular}

$\begin{array}{lr}\mathrm{M}=2-\mathrm{O} 1 & 1791(4) \\ \mathrm{M}=2-\mathrm{O} 6 & 1.966(4) \\ \mathrm{M}=2-\mathrm{N} 3 & 2.050(5) \\ \mathrm{M}=2-\mathrm{N} 4 & 2.054(5) \\ \mathrm{M}=2-\mathrm{O} 2 & 2.200(4) \\ \mathrm{M}=2-\mathrm{O} 9 & 2.00(4) \\ \mathrm{O}-\mathrm{M}=2-\mathrm{N} 3 & 166.5(2) \\ \mathrm{O} 1-\mathrm{M}=2-\mathrm{N} 4 & 1692(2) \\ \mathrm{O} 2-\mathrm{M}=2-\mathrm{O} 9 & 171.1(2) \\ \mathrm{O} 5-\mathrm{C} 29-\mathrm{C} 3-\mathrm{C} 35 & 50.3(9) \\ \mathrm{O} 2-\mathrm{C} 21-\mathrm{C} 22-\mathrm{C} 27 & 8(1)\end{array}$

987 "Standerd desictions in prentheses 
992 Table 4. Textural Properties of Materials SiO2-CTA, SiO2-Ex, SiO2-TMA, and [Mn2O]@SiO2

\begin{tabular}{|c|c|c|c|c|c|}
\hline & \multirow[b]{2}{*}{$500_{\text {NCTA }}$} & \multirow[b]{2}{*}{$\mathrm{SO}_{x} \mathrm{Ex}$} & \multirow[b]{2}{*}{500 TMA } & \multicolumn{2}{|c|}{$\left.\left(\mathrm{M} n_{1} \mathrm{O}\right] \mathrm{e}\right) \mathrm{es} \mathrm{O}_{1}$} \\
\hline & & & & far 1 & far 2 \\
\hline$d_{x o}=$ & 4.1 & & 4.1 & 41 & 41 \\
\hline$a_{0}{ }^{*}=$ & 47 & & 48 & 47 & 48 \\
\hline insmaity, ${ }^{2} 1 \times 10^{3}$ cosns & 100 & & 200 & 139 & 149 \\
\hline HWFH $2 \theta, \mathrm{dg}$ & 0.24 & & 023 & 0.27 & Q28 \\
\hline BET wutioe area $=^{1} g^{-1}$ & & 945 & & & \\
\hline$c$ & & $\infty 2$ & 73 & 53 & 50 \\
\hline poosed wolses, $=1 . g^{-1}$ & & 0.80 & 069 & 0.36 & 0.36 \\
\hline poes derese, ${ }^{2}=$ & & 38 & 37 & $28-3.4$ & $28-33$ \\
\hline
\end{tabular}

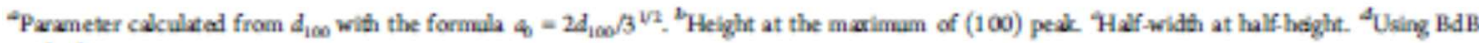


1002 Table 5. Summary of Catalytic Results for Compounds 1 and 2 with [H2O2]0 $=1.05 \mathrm{M}$ and [MnIII2] $=$ $1003 \quad 0.8 \mathrm{mM}$ in $\mathrm{CH} 3 \mathrm{CN}-\mathrm{H} 2 \mathrm{O}$ 9:1 (v/v)

1004

\begin{tabular}{|c|c|c|c|c|c|c|}
\hline \multirow[b]{2}{*}{ sxeple } & \multicolumn{2}{|c|}{ a 1 = } & \multicolumn{2}{|c|}{ at 2 min } & \multicolumn{2}{|c|}{ at 10 min } \\
\hline & $\mathrm{TON}^{2}$ & $8 \mathrm{H}_{1} \mathrm{O}_{2}{ }^{2}$ & $\mathrm{TCN}^{-2}$ & $8 \mathrm{H}_{x} \mathrm{O}_{1}{ }^{2}$ & $\mathrm{TON}^{-1}$ & $\% \mathrm{H}_{2} \mathrm{O}_{2}{ }^{2}$ \\
\hline 1 & 220 & 31 & 334 & 46 & 515 & 70 \\
\hline 2 & 182 & 25 & 2.57 & 35 & 437 & 60 \\
\hline
\end{tabular}

1005

"TON $=$ mand $\mathrm{O}_{2} / \mathrm{mmol} \mathrm{Mn}_{2}={ }^{1} \% \mathrm{H}_{2} \mathrm{O}_{2}$ decomposed.

1007

1008

1009

1010 
1013 Table 6. Summary of Catalytic Results for Compounds 1 and 2 and Material [Mn2O]@SiO2 with $1014[\mathrm{H} 2 \mathrm{O} 2] 0=1.05 \mathrm{M}$ and $[\mathrm{MnIII} 2]=0.8 \mathrm{mM}$ in $\mathrm{CH} 3 \mathrm{CN}-\mathrm{H} 2 \mathrm{O} 9: 1(\mathrm{v} / \mathrm{v})$

\begin{tabular}{|c|c|c|c|c|c|c|c|}
\hline \multirow[b]{2}{*}{ sanple } & \multirow[b]{2}{*}{$\mathrm{pH}$} & \multicolumn{2}{|c|}{ a 1 min } & \multicolumn{2}{|c|}{$x 2$ = } & \multicolumn{2}{|c|}{$x=10=$} \\
\hline & & $\mathrm{TON}^{-1}$ & $\% \mathrm{H}_{2} \mathrm{Q}_{2}^{2}$ & $\mathrm{TON}^{-1}$ & $\% \mathrm{H}_{2} \mathrm{O}_{2}^{2}$ & $\mathrm{TON}^{-}$ & $\% \mathrm{H}_{2} \mathrm{O}_{2}{ }^{2}$ \\
\hline$\left[\mathrm{M}{ }_{2} \mathrm{O}\right] \mathrm{es \textrm {SO } _ { 2 }}$ & 89 & 312 & 42 & 40 & 60 & 587 & 80 \\
\hline $\mathbf{1}$ & 60 & 227 & 34 & 334 & 46 & 515 & 70 \\
\hline 2 & 60 & 182 & 25 & 257 & 35 & 437 & 60 \\
\hline 2 & 7.3 & 295 & 40 & 366 & 50 & 514 & 70 \\
\hline 2 & 2.8 & 374 & 51 & 496 & 67 & 582 & 79 \\
\hline
\end{tabular}


1022 Table 7. Summary of Catalytic Results for Compounds 1 and 2 and Material [Mn2O]@SiO2 with $1023[\mathrm{H} 2 \mathrm{O} 2] 0=1.05 \mathrm{M}$ and $[\mathrm{MnIII} 2]=0.8 \mathrm{mM}$ in Water

\begin{tabular}{|c|c|c|c|c|c|c|}
\hline \multirow[b]{2}{*}{ areple } & \multicolumn{2}{|c|}{ xt 1 min } & \multicolumn{2}{|c|}{ at 2 mis } & \multicolumn{2}{|c|}{$x 10=\mathrm{m}$} \\
\hline & $\mathrm{TON}^{-1}$ & $* \mathrm{H}_{2} \mathrm{O}_{2}{ }^{2}$ & TON" & $\% \mathrm{H}_{2} \mathrm{O}_{2}{ }^{2}$ & $\mathrm{TON}^{-1}$ & $* \mathrm{H}_{2} \mathrm{O}_{2}{ }^{2}$ \\
\hline$\left[\mathrm{M}_{1} \mathrm{O}\right] \rho \mathrm{SO}_{2}$ & 98 & 13 & 180 & 25 & 514 & 70 \\
\hline 1 & 7 & 1 & 12 & 2 & 39 & 5 \\
\hline 2 & 6 & 1 & 10 & 1 & 39 & 5 \\
\hline
\end{tabular}

1024

${ }^{4} \mathrm{TON}=\operatorname{mmol} \mathrm{O}_{2} / \mathrm{mmol} \mathrm{Mn}_{2}={ }_{2}{ }^{4} \mathrm{H}_{2} \mathrm{O}_{2}$ deco mposed.

1025

1026

1027

1028

1029

1030 
1031 Table 8. Summary of Properties for Material [Mn2O]@SiO2 and Post-Catalysis Products 1032

Table 8. Summary of Properties for Material $\left[\mathrm{Mn}_{2} \mathrm{O}\right] @ \mathrm{SiO}_{2}$ and Post-Catalysis Products

\begin{tabular}{|c|c|c|c|}
\hline sarpie & movetrwature & poosus woluser, cel' $\mathrm{g}^{-1}$ & $\%$ max loos \\
\hline$[\mathrm{M}=1,0] e s: \mathrm{O}_{2}$ & rex & 0.36 & 21.9 \\
\hline$[\mathrm{M}=0 \mathrm{O}] \mathrm{es}=\mathrm{O}_{2}{ }^{\mathrm{m}}$ & rex & 0.58 & 7.4 \\
\hline$[\mathrm{M}=1$ O & $=0$ & & \\
\hline 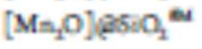 & $\mathrm{Fx}$ & 0.50 & 9.1 \\
\hline
\end{tabular}

1033

"Loss of the $\mathrm{Mn}$ complex's ligends in the ange of $200-400{ }^{\circ} \mathrm{C}$, according to TCA.

1034

1035 